OPEN ACCESS

Edited by:

Aicha Asma Houfani,

University of British Columbia,

Canada

Reviewed by:

Martina Aulitto,

University of Naples Federico II, Italy

Paola Monica Talia,

Consejo Nacional de Investigaciones

Científicas y Técnicas (CONICET),

Argentina

*Correspondence:

Digvijay Verma

digvijay.udsc@gmail.com

Specialty section:

This article was submitted to

Extreme Microbiology,

a section of the journal

Frontiers in Microbiology

Received: 21 June 2021

Accepted: 06 August 2021

Published: 09 September 2021

Citation:

Verma D (2021) Extremophilic Prokaryotic Endoxylanases: Diversity, Applicability, and Molecular Insights.

Front. Microbiol. 12:728475

doi: 10.3389/fmicb.2021.728475

\section{Extremophilic Prokaryotic Endoxylanases: Diversity, Applicability, and Molecular Insights}

\author{
Digvijay Verma* \\ Department of Environmental Microbiology, Babasaheb Bhimrao Ambedkar University, Lucknow, India
}

Extremophilic endoxylanases grabbed attention in recent years due to their applicability under harsh conditions of several industrial processes. Thermophilic, alkaliphilic, and acidophilic endoxylanases found their employability in bio-bleaching of paper pulp, bioconversion of lignocellulosic biomass into xylooligosaccharides, bioethanol production, and improving the nutritious value of bread and other bakery products. Xylanases obtained from extremophilic bacteria and archaea are considered better than fungal sources for several reasons. For example, enzymatic activity under broad $\mathrm{pH}$ and temperature range, low molecular weight, cellulase-free activity, and longer stability under extreme conditions of prokaryotic derived xylanases make them a good choice. In addition, a short life span, easy cultivation/harvesting methods, higher yield, and rapid DNA manipulations of bacterial and archaeal cells further reduces the overall cost of the product. This review focuses on the diversity of prokaryotic endoxylanases, their characteristics, and their functional attributes. Besides, the molecular mechanisms of their extreme behavior have also been presented here.

Keywords: prokaryotes, extremozymes, endoxylanases, lignocelluose, biobleaching

\section{INTRODUCTION}

The natural biomass of lignocellulose finds potential as an alternate energy source that exhibits the possibility to replace the nonrenewal energy sources. Lignocellulose is chiefly composed of cellulose (40\%), hemicellulose (33\%), and lignin (23\%) (Ninawe et al., 2008). Therefore, this natural biomass shares a significant proportion of sugars that can be used for bioethanol conversion as well as for several other biotechnological applications (Collins et al., 2005). However, the creeping growth in this technology is not commendable as would have been expected. Of the several reasons, the dearth of industrially fit enzymes/biocatalysts is one of the major reasons to lose this goal. The lignocellulolytic enzymes significantly participate in the conversion of complex biomass into valuable products (Bocchini et al., 2002; Cordeiro et al., 2002). Industries are primarily interested in cellulosic fibers for making quality papers (Collins et al., 2005; Bhardwaj et al., 2019) or for extracting sugars for bioethanol production (Bhalla et al., 2015; Xiao et al., 2019), where endoxylanases facilitate this process by removing xylan polysaccharides. Besides, the outstanding applications of xylooligosaccharides (XOs) as prebiotic further grab the attention to harvest this 
valuable natural resource (Dornez et al., 2011). At present, the CAZy database ${ }^{1}$ comprises 4,321 bacterial and 44 archaeal glycosyl hydrolase family 10 (GH-10) type xylanolytic enzymes, whereas the GH-11 family harbor 1,362 bacterial and only 11 archaeal representatives. Both of these xylanases share several common features, where both exhibit glutamate as catalytically important residues. However, amino acid compositions, molecular weight, 3D structures, and signature sequences categorize them in different families (Figure 1A). The GH-11 family xylanases are considered true xylanases due to their substrate specificity toward xylan (Paes et al., 2012; Yan et al., 2021).

Xylan is the main constituent of the hemicellulosic compounds that accounts for one-third of total organic carbon present on earth (Sharma et al., 2007; Kumar et al., 2013b). Therefore, not only does xylan act as a reservoir of sugars but also their degradation facilitates the release of cellulosic fibers from lignocellulosic material (Collins et al., 2005). In industries, this process occurs at very high temperatures and pressure under alkaline conditions to remove the xylan component from lignocellulosic material (Kumar and Satyanarayana, 2012). Such processes are energy-intensive and add a significant chunk of pollutants in the environments such as chlorine, dioxins, and other air pollutants (Sharma et al., 2017). Therefore, hemicellulases are preferred to reduce the harmful effects that occur during the chemical and mechanical treatments of hemicellulosic materials to make the process eco-friendly and cost-effective (Collins et al., 2005). Due to the extreme conditions of the industries, hemicellulases of extreme properties have always been in demand in industries for their applications. Hemicellulases are the bundle of enzymes that include endoxylanases, $\beta$-xylosidase, arabinofuranosidase, and acetyl-xylan esterase, among others (Bhardwaj et al., 2019). Endo (EC: 3.2.1.8) represents the chief enzyme of hemicellulases that cleave the $\beta$-glycosidic bonds of the xylan backbone and release XOs as a product, while the $\beta$-xylosidases (EC: 3.2.1.37) act on xylobiose or other xylooligosaccharides to generate monomeric sugar xylose as the final product. Arabinofuranosidases (EC: 3.2.1.55) and acetyl xylan esterases (EC: 3.1.1.72) attack on side chains of heterogeneous xylan substrate and assist xylanases and $\beta$-xylosidases for the complete degradation of xylan (Collins et al., 2005; Figure 1B). The synergistic effect of these enzymes removes the xylan as well as lignin from the cellulosic fibers in a specific and refined manner without affecting the quality of the cellulose (Sharma et al., 2007). In search of efficient enzymes, extremophilic microorganisms always come on the first choice as extremophiles are enough capable to perform this task due to the abundance of proteins or enzymes of extreme properties (Verma and Satyanarayana, 2020). These astonishing microorganisms represent themselves as the pioneer organisms that were evolved during the origin of the earth (Vieille and Zeikus, 2001). Therefore, the study of extremophiles always provokes researchers to reveal their hidden properties and the inherent mechanisms for their survival in extreme environments (Basit et al., 2018; Merino et al., 2019). The proteins and enzymes

${ }^{1}$ www.cazy.org have been reported to play a pivotal role in acquiring adaptations to several extremophiles. Such extremozymes exhibit several unique features that have been accumulated during evolution (Vieille and Zeikus, 2001). Several such enzymes were extensively explored in numerous ways to understand their mechanisms as well as for their applicability in several industries. Hemicellulosic extremozymes, therefore, enhance the interest due to acquired properties of their natural habitat. Although the hemicellulosedegrading enzymes have been discovered from bacteria to fungi, the majority of these enzymes have been of mesophilic origin (Collins et al., 2005; Bhardwaj et al., 2019). Such enzymes are not able to withstand the extreme conditions of the industries and deactivate during their employment in harsh conditions (Yang et al., 2017; Xiang et al., 2019). For example, xylanases find applicability in the bleaching of pulp samples in the paper industry (Viikari et al., 1986). However, the bleaching process of pulp in the paper industry occurs at very high temperature $\left(>90-105^{\circ} \mathrm{C}\right)$ and pressure (8-10 atmospheric pressure) under alkaline conditions $(\mathrm{pH}>8.5-11)$; therefore, thermo-alkalistable xylanases are required to meet these extreme conditions (Viikari et al., 1986; Kumar and Satyanarayana, 2012; Ayubi et al., 2021). An enzyme of mesophilic properties cannot perform well in such conditions and gets destroyed easily during the process. Several such requisites of the industries encourage the discovery of extremophilic hemicellulases. Therefore, recovering extremophiles from a specific environment is the first step of finding an enzyme of interest. Traditional cultivation approaches lose a significant portion of $99 \%$ of microorganisms of environmental samples (Amann et al., 1995; Handelsman, 2004). This count further enhances in the case of extremophilic microorganisms that are always present in lower count over the mesophilic microbes in any environment. Therefore, the cultivation of the extremophiles in the pure form of isolates is a tedious job that needs huge expertise and patience. Metagenomic approaches offer an alternate way to extract the entire community DNA (bacteria, archaea, and eukarya) of an environmental sample bypassing the cultivation of the microorganisms (Handelsman, 2004). The technique is considered the second most significant invention after the discovery of the microscope. The technique has been successfully employed for retrieving several novel genes of microbial enzymes and other bioactive molecules from diverse environments including extreme habitats (Ferrer et al., 2005; Prayogo et al., 2020). This review discusses the diversity and applicability of extremophilic endoxylanases in detail and provides molecular insights into the extremophilic xylanases.

\section{FONDNESS OF BACTERIAL ENDOXYLANASES OVER THE FUNGAL ORIGIN}

Hemicellulose-degrading microorganisms show their presence in all three domains of organisms. Prokarya and archaea are the major groups where extremophilic microorganisms are more abundant over eukarya. There are several reasons for considering bacterial endoxylanases over other microbial sources 


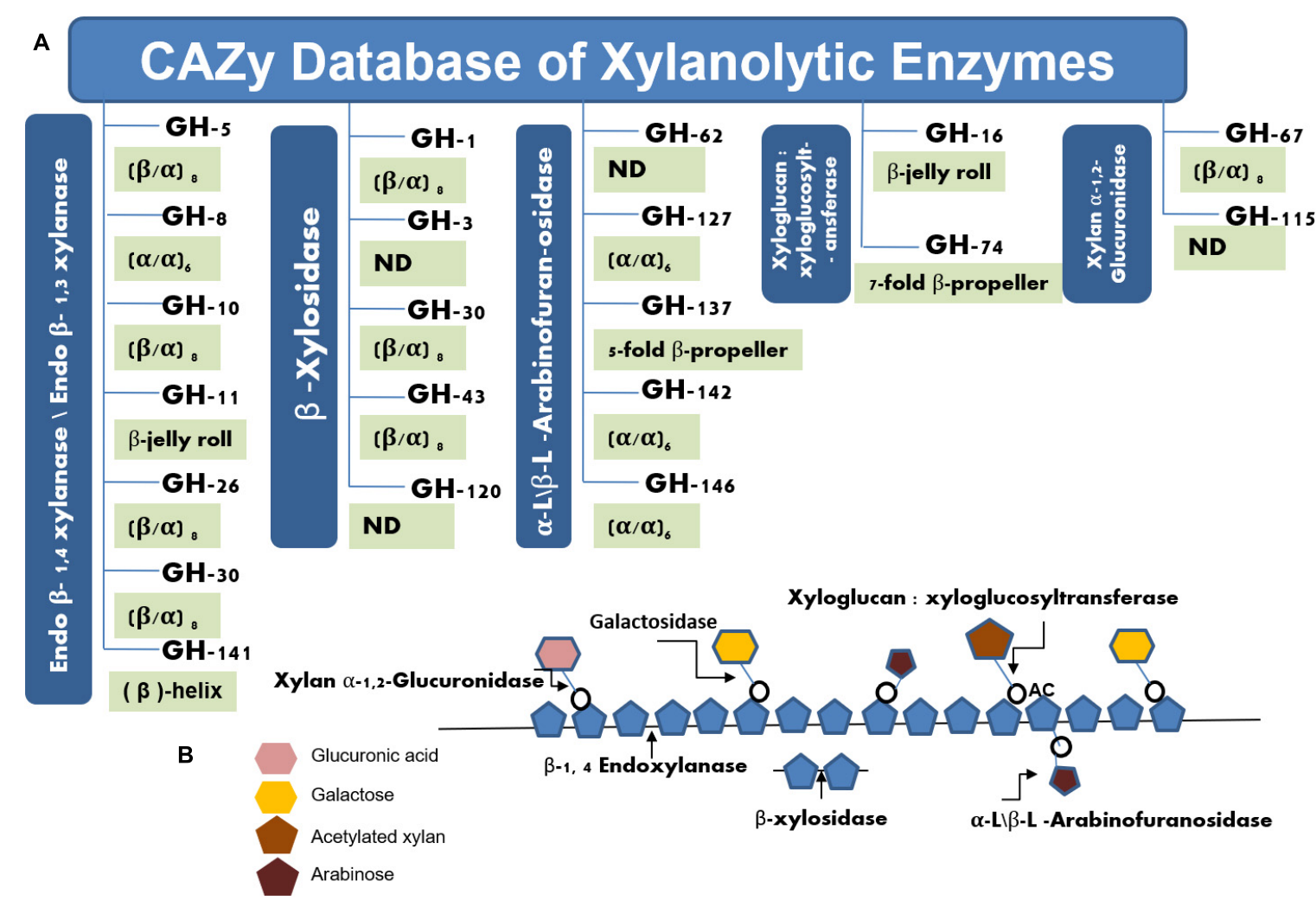

FIGURE 1 | Pictorial representation of various glycosyl hydrolases families having xylan hydrolytic enzymes (A). Schematic representation of various xylanolytic enzymes for their activity toward heterogeneous xylan (B).

(Zhu et al., 2011; Chakdar et al., 2016; Verma et al., 2019). Easy cultivation and harvesting of bacterial cells along with a short lifespan consider the bacteria an attractive factory for enzyme production (Verma et al., 2019). Besides, the biophysical and biochemical properties of bacterial hemicellulases such as wide $\mathrm{pH}(3.0-10.0)$ and temperature $\left(20-105^{\circ} \mathrm{C}\right)$ range further broaden their scope for their extensive applications in industries. The majority of the fungal xylanases are either acidic or neutral in their characteristics, while several bacterial xylanases have been reported for their optimum $\mathrm{pH}$ under alkaline conditions (Mamo et al., 2006; Amel et al., 2016; Yadav et al., 2018), which is a highly required property for the paper industry in bioleaching of pulp samples. The fungus also produces copolymers along with extracellular enzymes that significantly reduce the overall viscosity of the reaction mixture (Sharma et al., 2016). Moreover, bacterial hemicellulases are comparatively of low molecular weight over the fungal origin. Low molecular weight $(<30 \mathrm{kDa})$ hemicellulases diffuse rapidly into the rigid lignocellulosic biomass and thus enhance their oxygen penetration rate during the downstream processing over the high molecular weight (>30 kDa) homologs (Breccia et al., 1998; Sharma et al., 2016; Verma et al., 2019). Several fungal xylanases come along with cellulase activity (Subramaniyan and Prema, 2002; Polizeli et al., 2005) that sometimes is not apt for many industries, while the majority of the bacterial xylanases are devoid of such activity and therefore more xylan-specific over the fungal endoxylanases (Robledo et al., 2016). Fungal endoxylanases are being employed in the industries; it may be due to their high production over the bacterial origin, else bacterial endoxylanases provide better alternates than fungi. Fungal endoxylanases may be preferred when the reaction conditions are not extreme and only highly active endoxylanases are required. Of various extreme properties, thermostability is the chief concern of several industries. Many thermophilic $\left(45-65^{\circ} \mathrm{C}\right)$ and hyperthermophilic $\left(>65^{\circ} \mathrm{C}\right)$ bacteria have been reported to exhibit thermophilic endoxylanases. For instance, Thermotoga (Bok et al., 1994; Winterhalter et al., 1995; Shi et al., 2013), Clostridium (Rani and Nand, 2000; Heinze et al., 2017), Caldicellulosiruptor (Luthi et al., 1990), Geobacillus (Sharma et al., 2007; Kumar et al., 2013b; Verma et al., 2013a), Bacillus (Mamo et al., 2006; Kumar et al., 2013a), and Streptomycetes (Bajaj and Singh, 2010) are the major genera for exhibiting thermophilic endoxylanases. The majority of these bacteria have been isolated from thermophilic habitats, which could be the reason for showing the reflection of their environment in their properties (Saleem et al., 2012; Verma et al., 2019; Irfan et al., 2020). However, there are reports on endoxylanases from those bacteria that have not been isolated from extreme environments, even then exhibiting extreme properties. Members of Geobacillus are the wonderful examples of such bacteria that uncovered several enzymes of odd characteristics that significantly vary from their environmental conditions (Zeigler, 2014). A thermophilic 
endoxylanase of $B$. pumilus B20 was isolated from paper mill soil samples that showed the optimum temperature at $60^{\circ} \mathrm{C}$ under a slightly acidic $\mathrm{pH}$ of 6.5, despite their mesophilic origin (Geetha and Gunasekaran, 2017). Endoxylanase of Bacillus halodurans TSEV1 also showed extremophilic properties (Topt. $70^{\circ} \mathrm{C}$ and $\mathrm{pH} 9.0$ ) that were discovered from a paper effluent sample (Kumar and Satyanarayana, 2014). Similarly, many endoxylanases of Pseudomonas sp. XPB-6 (Sharma and Chand, 2012), Geobacillus thermoleovorans (Verma and Satyanarayana, 2012), Paenibacillus sp. HPL-001 (Hwang et al., 2010), and Streptomyces sp. S27 (Li et al., 2009) were isolated from mesophilic environmental samples that unveiled thermophilic properties on characterization. On the other hand, archaeal endoxylanases have been usually recovered from Crenarchaeotes such as Thermosphaera aggregans (Huber et al., 1998), Acidilobus saccharovorans (Menasria et al., 2018), and Sulfolobus solfataricus (Cannio et al., 2004). On characterization, the majority of these archaeal endoxylanases showed outstanding thermostability at higher temperatures but under acidic conditions.

\section{BIOPHYSICAL PROPERTIES OF EXTREMOPHILIC ENDOXYLANASES}

The GH-10 and GH-11 xylanases of either bacteria, archaea, or fungal origin share several common features such as both exhibiting glutamate as catalytic acid/base in their respective signature sequences and both following the retaining mechanism of catalysis (Figure 2). In both families, several extremophilic endoxylanases have been characterized. Extremophilic properties of hemicellulases make them different from the mesophilic homologs. These enzymes have immense significance in several industries. The thermo-alkali-stable xylanases find potential application in the bleaching of pulp in the paper industry. Similarly, thermo-acid-stable xylanases and xylosidases have employability in the bread, feed, and juice industries. Characterization of such hemicellulases uncovers several biochemical and biophysical properties of hemicellulases (Table 1).

\section{Thermophilic Endoxylanases}

Thermotogales is one of the orders of bacteria that harbor promising candidates that can withstand extreme environmental conditions. Several endoxylanases of genus Thermotoga have been identified for thermophilic hemicellulases for exhibiting their optimum temperature (Topt.) beyond $70^{\circ} \mathrm{C}$. A thermophilic endoxylanase (XynA) of GH-10 family from Thermotoga sp. strain FjSS3-B.1 is one of the most thermostable xylanases reported to date that showed maximum activity at $105^{\circ} \mathrm{C}$. Several such xylanases from Thermotoga spp. such as T. thermarum (Shi et al., 2014) and T. naphthophila (Hamid and Aftab, 2019), Thermotoga neapolitana (Zverlov et al., 1996), and Thermotoga petrophila (Ikram et al., 2012) have been reported for having hyper-thermophilic xylanases.

Bacillus and Geobacillus represent another major group of bacteria that exhibit plenty of thermophilic endoxylanases. Bacillus such as Bacillus stearothermophilus (Topt. $60^{\circ} \mathrm{C}$; Nammori et al., 1990), Bacillus stearothermophilus SDX (Topt. $70^{\circ} \mathrm{C}$; Dhiman et al., 2008), Bacillus licheniformis A99 (Topt. $60^{\circ} \mathrm{C}$; Archana and Satyanarayana, 1998), Bacillus pumilus MK001 (Topt. $60^{\circ} \mathrm{C}$; Kapoor et al., 2008), Bacillus halodurans (Topt. $60^{\circ} \mathrm{C}$; Mamo et al., 2006), Bacillus amyloliquefaciens (Topt. $80^{\circ} \mathrm{C}$; Breccia et al., 1998), and Bacillus circulans D1 (Topt. $60^{\circ} \mathrm{C}$; Bocchini et al., 2008) have been reported for thermophilic xylanases. An alkaliphilic species of $B$. halodurans

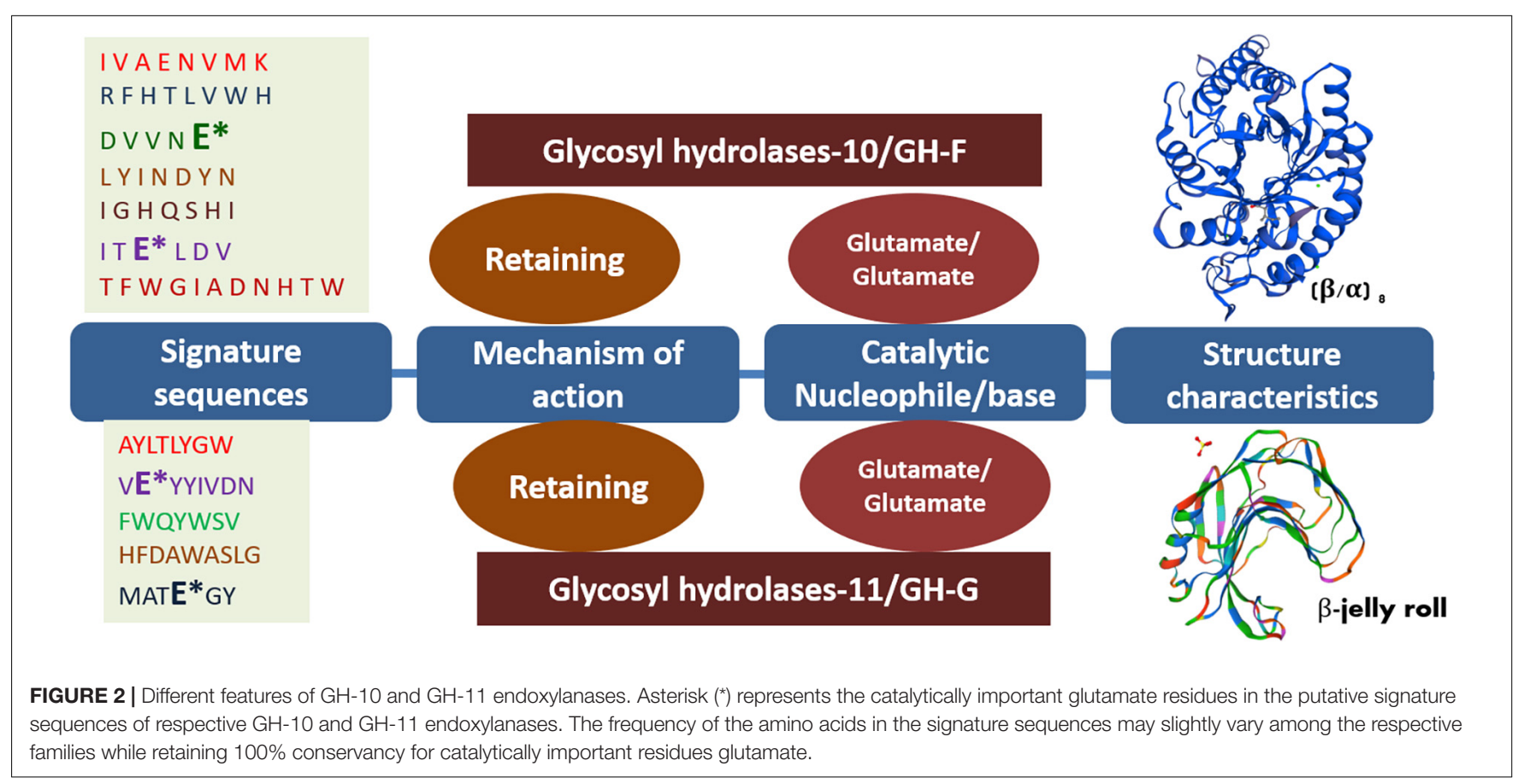


TABLE 1 | Characteristics of extremophilic endoxylanases from various prokaryotic microorganisms.

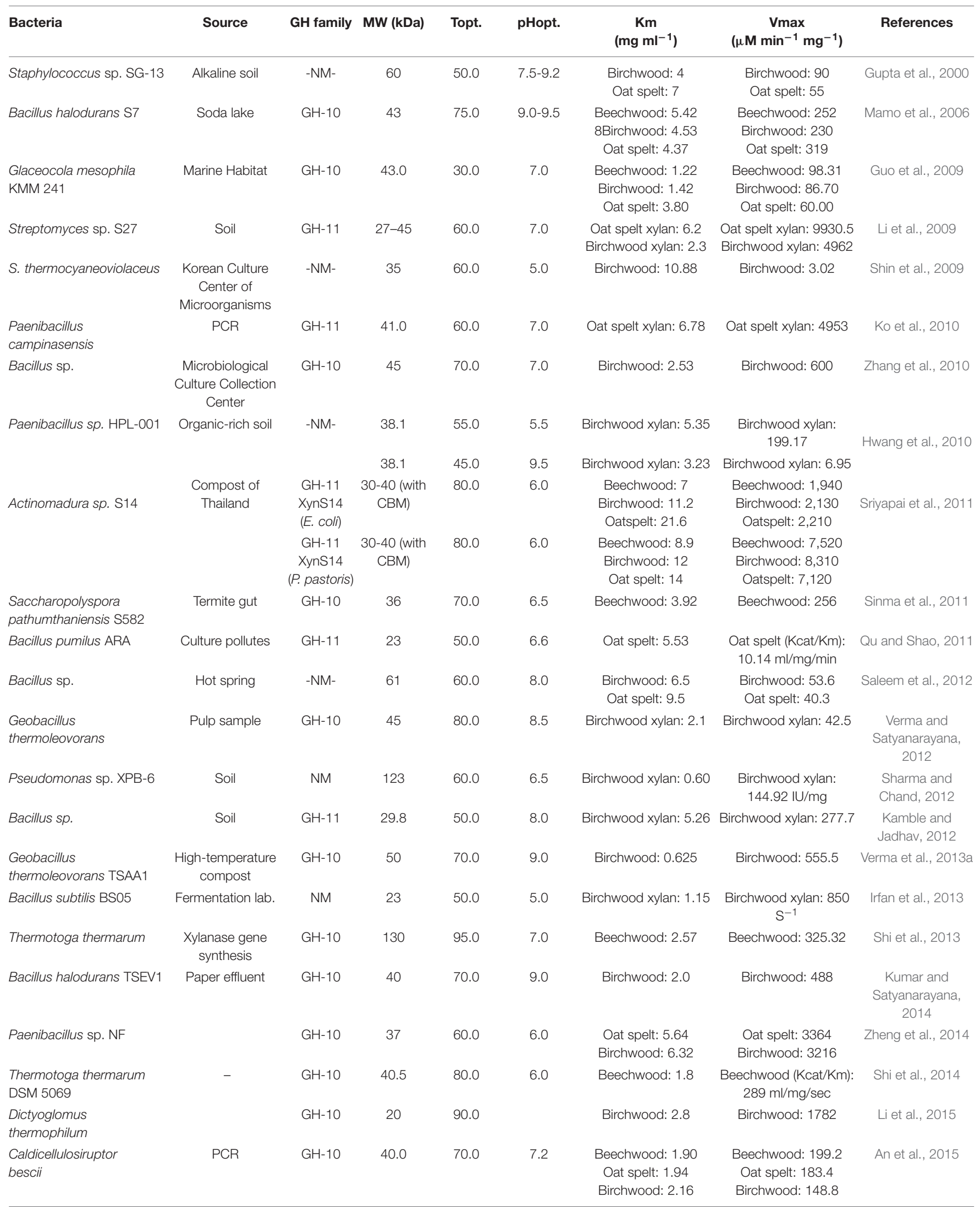


TABLE 1 | (Continued)

\begin{tabular}{|c|c|c|c|c|c|c|c|c|}
\hline Bacteria & Source & GH family & MW (kDa) & Topt. & pHopt. & $\begin{array}{c}\mathrm{Km} \\
\left(\mathrm{mg} \mathrm{ml}^{-1}\right)\end{array}$ & $\begin{array}{c}\text { Vmax } \\
\left(\mu \mathrm{M} \min ^{-1} \mathrm{mg}^{-1}\right)\end{array}$ & References \\
\hline $\begin{array}{l}\text { Streptomyces coelicolor } \\
\text { A3(2) }\end{array}$ & Soil & $\mathrm{GH}-10$ & 47.0 & 60.0 & 6.0 & Beechwood: 0.24 & Beechwood: 6.86 & $\begin{array}{l}\text { Enkhbaatar et al., } \\
2016\end{array}$ \\
\hline $\begin{array}{l}\text { Caldicoprobacter } \\
\text { algeriensis } \mathrm{THC} 1(\mathrm{~T})\end{array}$ & $\begin{array}{l}\text { Hydrothermal hot } \\
\text { spring }\end{array}$ & $\mathrm{GH}-11$ & 35.0 & 70.0 & 11.0 & Oat spelt xylan: 1.33 & Oat spelt xylan: 595 & Amel et al., 2016 \\
\hline $\begin{array}{l}\text { Saccharophagus } \\
\text { degradans 2-40 }\end{array}$ & ATCC & $\mathrm{GH}-10$ & 42.4 & 30.0 & 7.0 & Birchwood xylan: 10.4 & Birchwood xylan: 253 & Ko et al., 2016 \\
\hline Bacillus pumilus B20 & Paper mill soil & NM & 85 & 60.0 & 2.3 & Oat spelt: 2.3 & Oat spelt: 50 & $\begin{array}{c}\text { Geetha and } \\
\text { Gunasekaran, } 2017\end{array}$ \\
\hline $\begin{array}{l}\text { Anoxybacillus } \\
\text { kamchatkensis NASTPD13 }\end{array}$ & Geyser valley & NM & 37 & 65.0 & 9.0 & Beechwood: 0.7 & Beechwood: 66.64 & Yadav et al., 2018 \\
\hline Bacillus licheniformis DM5 & Water & $\mathrm{GH}-30$ & 38 & 50.0 & 6.5 & Beechwood: 1.5 & Beechwood: $2.7 \mathrm{U} / \mathrm{ml}$ & Ghosh et al., 2019 \\
\hline Bacillus licheniformis S3 & Hot spring & $-\mathrm{NM}-$ & $-\mathrm{NM}-$ & 55.0 & 6.0 & Xylan: 8.6 & Xylan: 43.71 & Irfan et al., 2020 \\
\hline $\begin{array}{l}\text { Bacillus subtilis strain CAM } \\
21\end{array}$ & $-\mathrm{NM}-$ & $\mathrm{GH}-11$ & 24 & 50.0 & 7.0 & Birchwood xylan: 2.9 & $\begin{array}{l}\text { Birchwood xylan: } \\
15207\end{array}$ & $\begin{array}{l}\text { Monica and } \\
\text { Kapoor, } 2021\end{array}$ \\
\hline
\end{tabular}

NM, not mentioned.

S7 isolated from an Ethiopian soda lake revealed an endoxylanase of polyextremophilic properties by retaining $100 \%$ of total endoxylanase activity even after $12 \mathrm{~h}$ of incubation at $50^{\circ} \mathrm{C}$ (Mamo et al., 2006). Another strain of B. halodurans isolated from Sambhar Lake, India, also shares similar biophysical properties with an optimum temperature at $70^{\circ} \mathrm{C}$ (Kumar and Satyanarayana, 2012). Moreover, this recombinant endoxylanase was active in the broad temperature range of $30^{\circ} \mathrm{C}$ to $100^{\circ} \mathrm{C}$, where it showed a half-life of $30 \mathrm{~min}$ at $80^{\circ} \mathrm{C}$. An unidentified species of Bacillus NG-2 has been identified for thermostable endoxylanase that exhibited $\mathrm{T}_{1 / 2}$ of $75 \mathrm{~min}$ at the optimum temperature of $70^{\circ} \mathrm{C}$ (Gupta et al., 2000). Similarly, the endoxylanases of Bacillus sp. GRE7 (Kiddinamoorthy et al., 2008) and B. firmus (Chang et al., 2004) also showed their maximum enzymatic activity at $70^{\circ} \mathrm{C}$. A novel $\mathrm{GH}-10$ thermostable endoxylanase of Bacillus sp. KW1 (Topt. $65^{\circ} \mathrm{C}$ ) showed activity over a wide range of substrates including carboxymethyl cellulose (CMC) and cellobiose (Wang et al., 2019). Besides, a plethora of enzymes have been documented from several Bacillus spp. that find their optimum temperature at or below $50^{\circ} \mathrm{C}$ such as B. amyloliquefaciens (Breccia et al., 1998), Bacillus stearothermophilus SSP34 (Subramaniyan and Prema, 2002), B. amyloliquefaciens strain SK-3 (Kumar et al., 2017), and Paenibacillus campinasensis BL11 (Ko et al., 2010).

Geobacillus, another very close genus of Bacillus that is usually present in hot and arid soil, has been identified for having endoxylanases of thermophilic characteristics. The member of this genera grabbed huge attention due to the presence of several thermostable proteins and enzymes that find potential biotechnological applications. Geobacillus thermoleovorans (Verma and Satyanarayana, 2012), G. thermoleovorans AP07 (Sharma et al., 2007), and Geobacillus thermodenitrificans TSAA1 (Verma et al., 2013a) are well known for their polyextremophilic endoxylanases. The source of these isolates is majorly from thermophilic environments; therefore, the selection of samples enhances the possibility to get the desired enzymes. A recombinant endoxylanase $G$. thermoleovorans isolated from pulp samples of a paper industry showed its activity over a broad range of temperature from 40 to $100^{\circ} \mathrm{C}$ with an optimum temperature of $80^{\circ} \mathrm{C}$. More interestingly, this enzyme exhibited a half-life of $1 \mathrm{~h}$ at $80^{\circ} \mathrm{C}$, which makes it suitable for several industries (Verma and Satyanarayana, 2012). A thermophilic bacterium $G$. thermodenitrificans TSAA1 isolated from a high-temperature compost plant in Fukuoka, Japan, was uncovered for a thermostable endoxylanase with an optimum temperature at $70^{\circ} \mathrm{C}$ along with a half-life of $10 \mathrm{~min}$ at $80^{\circ} \mathrm{C}$ and was successfully employed for saccharifying agroresidues (Verma et al., 2013a). This recombinant enzyme showed high homology with the GH-10 endoxylanases of other close species of Geobacillus such as G. thermodenitrificans, G. thermoleovorans, and G. stearothermophilus. Bhalla et al. (2014, 2015) reported the most promising thermostable endoxylanase from Geobacillus WSUCF1 that showed outstanding stability of 12 days by retaining $50 \%$ of total enzymatic activity at $70^{\circ} \mathrm{C}$. The group further claimed that this enzyme is the most thermostable enzyme from any other species of Geobacillus to date. Besides, there are several species/strains of Geobacillus that find their optimum temperature at or below $60^{\circ} \mathrm{C}$ such as xylanases of $G$. thermodenitrificans (Irfan et al., 2018), G. stearothermophilus KIBGE-IB29 (Bibi et al., 2018; Mathew et al., 2018), and Geobacillus strain DUSELR 13 (Bibra et al., 2018). Although Geobacillus are obligate thermophiles (Topt. of growth $55-65^{\circ} \mathrm{C}$ ), even their presence is not limited to thermophilic environments; rather, numerous Geobacillus spp. have been isolated from mesophilic as well as low-temperature environments (Zeigler, 2014). Overall, it has been observed that the majority of xylanolytic enzymes recovered from Geobacillus spp. exhibit thermostability under acidic as well as alkaline conditions for the longer duration that prove their suitability for various biotechnological applications.

Clostridium absonum CFR-702 (Rani and Nand, 2000), Dictyoglomus sp. B1 (Adamsen et al., 1995), Rhodothermus marinus ITI376 (Dahlberg et al., 1993), and Thermoactinomyces thalophilus sub gr. C (Kohilu et al., 2001) are the other bacterial 
species reported for thermophilic endoxylanases, where xylanase of Arthrobacter sp. MTCC 5214 has been reported for exhibiting extreme endoxylanase activity even at $100^{\circ} \mathrm{C}$ (Khandeparkar and Bhosle, 2006). The genus Caldicellulosiruptor also represents hyperthermophilic, Gram-positive anaerobes and has been reported as a reservoir of GH-10 thermostable xylanases (Luthi et al., 1990; Liu et al., 2017; Jia and Han, 2019), C. lactoaceticus (Topt. $80^{\circ} \mathrm{C}$; Jia et al., 2014), and C. owensensis (T opt. $90^{\circ} \mathrm{C}$; Liu et al., 2016). Moreover, these xylanases were stable at higher temperatures for long durations and therefore find suitability in bleaching of pulp samples. For instance, the recombinant xylanase (CoXynA) retains 50\% of its total activity even after $1 \mathrm{~h}$ of incubation at $80^{\circ} \mathrm{C}$ (Liu et al., 2018). These enzymes have been successfully employed for the generation of XOs from lignocellulosic biomass. The Caldicellulosiruptor is considered as one of the most promising sources of hemicellulases that exhibit an exceptional potential to deconstruct the lignocellulosic material. To further improve the overall lignocellulose-degrading activity of $C$. bescii, two xylanase-encoding genes of Acidothermus cellulolyticus were cloned and expressed in C. bescii which resulted in a significant increase in the exoproteome of $C$. bescii on xylan substrates (Kim et al., 2016).

A unique GH-10 endoxylanase (XynDZ5) was recovered from a Thermoanaerobacterium species isolated from an Icelandic hot spring. On characterization, it was identified as a highly thermostable endoxylanase with optimum activity between 65 and $75^{\circ} \mathrm{C}$. Interestingly, it showed very low identity of $26 \%$ with the other close homologs (Zarafeta et al., 2020). Similarly, a hyperthermophilic bacterium Stenotrophomonas maltophilia produced high molecular weight xylanase that showed fair stability in a wide range of temperature $\left(30-80^{\circ} \mathrm{C}\right)$. Thermostable xylanases of Clostridium absonum CFR-702 (Rani and Nand, 2000), Dictyoglomus sp. B1 (Adamsen et al., 1995), Clostridium cellulovorans (Sleat et al., 1984), Thermopolyspora flexuosa (Anbarasan et al., 2017), and Rhodothermus marinus (Dahlberg et al., 1993) are also notable.

\section{Alkaliphilic Endoxylanases}

The alkalophilicity of endoxylanases is another important parameter of several many industries especially the paper and pulp industry. The majority of the Geobacillus spp. produce alkaliphilic hemicellulases. The recombinant xylanases of G. thermoleovorans AP07 (pHopt. 8.0; Verma and Satyanarayana, 2012), G. thermodenitrificans A333 (pHopt. 7.5; Marcolongo et al., 2015), G. thermoleovorans (pHopt. 8.5; Sharma et al., 2007), and Geobacillus sp. WBI (pHopt. 6-9; Mitra et al., 2015) have also been well documented for alkaliphilic endoxylanases. However, xylanases of $G$. thermodenitrificans TSAA1 (pHopt. 7.0; Verma et al., 2013a), G. strain DUSELR13 (pHopt. 7.0; Bibra et al., 2018), and G. stearothermophilus KIBGE-IB29 (pHopt. 6.0; Bibi et al., 2018) behaved differently by showing their optimum $\mathrm{pH}$ from slightly acidic to neutral range. Besides optimum $\mathrm{pH}$ in the alkaline range, the stability of these xylanases at higher $\mathrm{pH}$ makes them eligible to withstand the industrial extreme conditions. The recombinant xylanases of Geobacillus sp. WBI (Mitra et al., 2015) and G. thermodenitrificans A333 (Marcolongo et al., 2015) were highly stable that can withstand the higher $\mathrm{pH}$ of 11.0 by retaining 97 and $75 \%$ of activity for $1 \mathrm{~h}$, respectively. The endoxylanases from $G$. thermoleovorans (Verma and Satyanarayana, 2012) and G. thermodenitrificans TSAA1 (Verma et al., 2013a) were successfully employed for the saccharification of the agro-residues for the liberation of xylooligosaccharides. Numerous highly alkaliphilic endoxylanases have been reported from several strains of B. halodurans (Mamo et al., 2006; Kumar and Satyanarayana, 2011, 2012) that find their optimum $\mathrm{pH} 8.0$ and above along with fair stability for long hours under high alkaline conditions. A polyextremophilic endoxylanase of $B$. halodurans TSEV1 was successfully employed for the bleaching of kraft pulp at the higher $\mathrm{pH}$ of 10.0 (Kumar and Satyanarayana, 2012). This first report of bleaching by endoxylanase of $B$. halodurans significantly reduced the kappa number by $14.6 \%$ and enhanced the brightness by $5.6 \%$. Gupta et al. (2015) reported the employment of thermo-alkalistable laccases and xylanases of Bacillus sp. and B. halodurans in bio-bleaching of pulp as well as in deinking of old newsprints. Of several Bacillus spp., B. stearothermophilus SDX (Dhiman et al., 2008), Bacillus subtilis (Annamalai et al., 2009), Bacillus strain Sam3 (Chaiyaso et al., 2011), P. campinasensis BL11 (Ko et al., 2010), Bacillus spp. (Kamble and Jadhav, 2012), and B. halodurans (Kumar et al., 2013a) have been identified for alkaliphilic endoxylanases and successfully employed in several industrial applications.

\section{Acidophilic Endoxylanases}

Acidic xylanases find application majorly in baking, juice, and feed industries. Fungi are well known for the secretion of several acidic xylanases. However, due to their short life span under acidic conditions and high molecular weight, bacteria and archaea were also explored for acidophilic xylanases. B. circulans D1 (pHopt. 5.0; Bocchini et al., 2008), Paenibacillus macerans IIPSP3 (pHopt. 4.5; Dheeran et al., 2012), and Streptomyces mexicanus HY-14 (pHopt. 5.5; Kim et al., 2014) represent highly acidophilic xylanases with an optimum activity at or near 5.0 $\mathrm{pH}$. Interestingly, the xylanases produced from P. macerans IIPSP3 and S. mexicanus HY-14 both were recovered from insect guts themselves in an acidic environment, and therefore could reflect the inherent characteristics in their enzymes. The endoxylanase of S. mexicanus HY-14 was successfully employed for the generation of XOs from birchwood xylan, while the high molecular weight $(205 \mathrm{kDa})$ endoxylanase of $P$. macerans IIPSP3 may find applicability in bioethanol production as well as in paper bleaching due to two $\mathrm{pH}$ optima, i.e., " $\mathrm{pH} 4.5$ and $\mathrm{pH}$ 9.0" (Dheeran et al., 2012). Compost soil-derived xylanases also show acidic behavior. Three xylanases have been recovered from compost soil metagenome showing their optimum $\mathrm{pH}$ (5.0-6.5) under the acidic region. Here, metagenomic xylanase (MXyl) derived from compost soil shows an exceptional behavior by exhibiting optimum pH of 9.0 (Verma et al., 2013b). Besides, endoxylanases produced from Thermotoga thermarum (Shi et al., 2014), B. subtilis CHO40 (Khandeparker et al., 2011), Caulobacter crescentus (Graciano et al., 2015), and Bacillus pumilus B20 (Geetha and Gunasekaran, 2017) also find their optimum pH at around 6.0. The majority of these xylanases have been employed for XO production. 


\section{Halophilic Endoxylanases}

Halophilic and halotolerant enzymes have immense applications in various industries. Several downstream processes of industries such as the bioethanol production and paper industries occur in high salt concentration; therefore, more halophilic enzymes are required (Amoozegar et al., 2019). Usually, these enzymes come along with alkaliphilic or thermophilic properties that make them more suitable for industries and therefore exhibit polyextremophilic properties. Halotolerant/halophilic hemicellulases find utility in almost every industry (Setati, 2010). Several bacteria have been reported for the presence of halophilic endoxylanases (Hung et al., 2011; Ghadikolaei et al., 2019). Guo et al. (2009) reported the first salt-tolerant xylanase from a marine bacterium Glaciecola mesophila KMM that was able to retain $90 \%$ of activity at a higher concentration of $2.5 \mathrm{M} \mathrm{NaCl}$. Similarly, a novel GH-10 family halophilic and thermostable endoxylanase reported from another marine bacterium Thermoanaerobacterium saccharolyticum NTOU1 found its optimum activity at $12.5 \% \mathrm{NaCl}(\mathrm{w} / \mathrm{v})$ concentration (Hung et al., 2011). A more halophilic xylanase produced from a halophilic alkali-tolerant bacterium Chromohalobacter sp. TPSV 101 showed its optimum activity at $20 \% \mathrm{NaCl}(\mathrm{w} / \mathrm{v})$ under a highly alkaline $\mathrm{pH}$ of 9.0 (Prakash et al., 2009). Therefore, this polyextremophilic enzyme may be employed in the seafood processing and juice industries. In a conventional approach of xylanase production from a novel halophilic bacterium, $15 \% \mathrm{NaCl}(\mathrm{w} / \mathrm{v})$ yielded maximum xylanase production, where the endoxylanase was of halophilic properties (Sanghvi et al., 2014). Novel halophilic xylanase was obtained from a halophilic marine bacterium Marinimicrobium sp. LS-A18. XylM18. This recombinant xylanase (XylM18) exhibited weak activity in the absence of salt but found stimulation in overall activity in the presence of $\mathrm{NaCl}$ up to the concentration of $25 \%(\mathrm{w} / \mathrm{v})$ ( $\mathrm{Yu}$ et al., 2019). Similarly, the recombinant xylanase (rXynAHJ14) from Bacillus sp. HJ14 retained $62 \%$ xylanase activity at a wide range of salt concentrations of 3-30\% (Zhou et al., 2014). Such enzymes find suitability in the processing of seafood/feed and best fit for the aquaculture industry. An extracellular endoxylanase from $G$. thermodenitrificans A333 showed fair activity up to $3 \mathrm{M}$ $\mathrm{NaCl}$ by retaining $70 \%$ residual activity for $1 \mathrm{~h}$ (Marcolongo et al., 2015). Recombinant xylanase (Xyn11-1) exhibited high salt-tolerant activity by retaining $77.4 \%$ residual activity at $0.25-4$ $\mathrm{M} \mathrm{NaCl}$ concentration (Wang et al., 2017). This enzyme is the first report of GH-11 xylanase that was obtained from salinealkali soil with polyextremophilic properties. Therefore, they may find several industrial applications.

\section{Psychrophilic Endoxylanases}

A very few psychrophilic xylanases have been reported from cold habitats (Van Petegem et al., 2003; Dornez et al., 2011; Wang et al., 2011, 2012; Chen et al., 2013; Qiu et al., 2017). Cold active xylanases have significance in several industries such as food processing, textile, oil extraction, and juice industries (Shallom and Shoham, 2003; Collins et al., 2006). The psychrophilic xylanases have been employed successfully in increasing the dough volume of bread in baking industries (Dornez et al., 2011).
The process of dough resting requires cold-active xylanases that can hydrolyze the hemicellulosic content of the bread and improve the quality of the bread by improving the softness, sweetness, and aroma (Dornez et al., 2011; Chen et al., 2013). One of the previous reports describes eight psychrophilic xylanases from the arctic region. Of them, one cold-active xylanase (xyn8) of Pseudoalteromonas sp. showed unique features by exhibiting specificity toward xylan only and devoid of activity on aryl- $\beta$-glycosides of xylobiose or xylotriose (Collins et al., 2005). All eight enzymes found applicability in the baking industry. Several psychrophilic enzymes including xylanase and $\beta$-xylosidase were obtained from a psychrotroph (Clostridium strain PXYL1) isolated from a cold-adapted cattle manure biogas digester. This endoxylanase revealed optimum activity at $20^{\circ} \mathrm{C}$ with a fair stability at $20^{\circ} \mathrm{C}$ for $2 \mathrm{~h}$ (Akila and Chandra, 2003). A novel cold-active xylanase-encoding gene (xyn27) was retrieved from metagenomic DNA of frozen soil in Daxinganling, China, which revealed optimum activity at $35^{\circ} \mathrm{C}$ along with 60.25 and $38.70 \%$ residual activity at 20 and $10^{\circ} \mathrm{C}$, respectively, under neutral $\mathrm{pH}$ having xylobiose as a major product (Qiu et al., 2017). Further characterization of this enzyme showed its multimetal tolerance activity and proposed its application in the food processing industry (Qiu et al., 2017). The members of Bacteriodetes are considered as a good reservoir of hemicellulosedegrading enzymes. Flavobacterium johsoniae, a Bacteriodetes, was isolated from mosquito larvae and explored for hemicellulase enzyme activity (Chen et al., 2013). A cold-active xylanase (xyn10A) was isolated from this bacterium that exhibited best activity at $30^{\circ} \mathrm{C}$ under alkaline $\mathrm{pH}$ of 8.0 . This modular enzyme was able to retain $50 \%$ of its total activity at $4^{\circ} \mathrm{C}$. Another novel cold-active xylanase (xynA) from Sorangium cellulosum found its maximum activity in the range of $30-35^{\circ} \mathrm{C}$ under neutral $\mathrm{pH}$ which successfully retained $\sim 33 \%$ of its total activity at $5^{\circ} \mathrm{C}$ (Wang et al., 2012). A halophilic cold-active xylanase (XynA) was characterized from a marine Gram-negative aerobic bacterium (Zunongwangia profunda) which also showed optimum activity at $30^{\circ} \mathrm{C}$ under slightly acidic conditions (Liu et al., 2014). The enzyme activity was increased by $180 \%$ in $3 \mathrm{M} \mathrm{NaCl}$, which retained $100 \%$ activity at $5 \mathrm{M} \mathrm{NaCl}$. Sequence analysis unveiled novel xylanase by showing a maximum identity of $42.7 \%$ only with xylanase of Bacillus sp. SN5. Compared to the mesophilic and thermophilic endoxylanases, psychrophilic xylanase count is less and needs to be further explored as the majority of the psychrophilic xylanases showed its optimum activity at or above $30^{\circ} \mathrm{C}$.

\section{ARCHAEAL ENDOXYLANASES}

Archaea may be considered as a synonym of extremophiles due to their abundance in extreme habitats (Cabrera and Blamey, 2018). This group of extreme prokaryotes has also been explored for recovering hemicellulases especially thermophilic endoxylanases (Verma and Satyanarayana, 2020). Two strains of Thermophilum were the first to be reported from archaeal isolates for having putative hemicellulase activity (Bragger et al., 1989). However, these enzymes were not extensively characterized for their 
biophysical and biochemical properties. Therefore, xylanases produced from Thermococcus zilligii strain A1 may be considered as the first report on characterized endoxylanases (Uhl and Daniel, 1999). The count of archaeal xylanases is comparatively low from bacterial xylanases due to several reasons such as (i) presence of low biomass of archaeal communities in an environmental sample, (ii) inappropriate cultivation strategies for isolating archaea, (iii) inefficient capability to utilize xylan substrate as a carbon source, and (iv) inaccessibility to obtain unculturable archaeal candidates. Therefore, archaeal biology is comparatively tedious to handle as compared to bacterial ones. However, a handful of reports on archaeal xylanases encourage to find more candidates from the extreme environment of archaeal origin. The endoxylanase of Thermococcus zilligii strain A1 was highly thermophilic, having a half-life of $8 \mathrm{~min}$ at $100^{\circ} \mathrm{C}$ (Uhl and Daniel, 1999). The endoxylanase was xylan specific and did not show activity toward other polysaccharides. Further analysis on this xylanase revealed that the $\mathrm{N}$-terminal sequence of this xylanase was more similar to the N-terminal sequence of T. zilligii maltodextrin phosphorylase (Rolland et al., 2002). Wainø and Ingvorsen (2003) further claimed the first characterization of thermophilic hemicellulases of archaeal origin. This archaeon has been identified as Halorhabdus utahensis that showed xylanase as well as $\beta$-xylosidase activities. On characterization, both of these enzymes showed their temperature optima in the hyperthermophilic range, i.e., above $60^{\circ} \mathrm{C}$. Besides, both shared halophilic properties by having activity up to $30 \% \mathrm{NaCl}$ (w/v) concentration. Similarly, a hyperthermophilic archaeon Pyrodictium abyssi produced an extremely thermostable xylanase that showed its activity at $105^{\circ} \mathrm{C}-110^{\circ} \mathrm{C}$. It is one of the most thermophilic xylanases reported so far from any archaeal sources (Andrade et al., 2001). Several polysaccharides have been used as an inducer for the production of xylanase as well as $\beta$-xylosidases. Sunna and Antranikian (1997) reported problems for not utilizing xylan substrates by several archaeal isolates, so pretreated xylan, i.e., autoclaved xylan, was used to enrich the medium for isolating xylanase-producing archaea. However, in recent years several archaea have been isolated by using untreated xylan as a sole carbon source (Kublanov et al., 2009; Gavrilov et al., 2016). Such archaea were explored for harnessing endoxylanases. An archaea Thermococcus sp. strain 2319x1 was successfully obtained by using sole xylan as a carbon source and showed optimum growth at $85^{\circ} \mathrm{C}$ under neutral $\mathrm{pH}$. A novel glycosidase gene of Thermococcus sp. strain 2319x1 was heterologously cloned and expressed in E. coli that revealed five domain structures, where three were coding glycoside hydrolases and two were carbohydrate-binding modules. Therefore, this protein was of very high molecular weight along with broad substrate activity on various polysaccharides (Gavrilov et al., 2016). It has been observed that archaeal xylanases exhibit highly thermostable characteristics that are suitable to withstand the extreme condition of the industries; however, these xylanases are active in either neutral or acidic regions. To the best of our knowledge, no archaeal xylanase has been reported to have alkaliphilic properties to date. When the majority of xylanases used in industries are of either fungal or bacterial origin, the employment of archaeal endoxylanase in industries is still very far with such limitations. With several protein engineering tools, the existing archaeal endoxylanases can be improved for their shelf-life and make them alkaliphilic for their true applications in industries.

\section{EXTREMOPHILIC XYLANASES OF UNCULTURABLE SOURCES}

Direct cloning of the community DNA and their analysis for recovering the product of interest made this technology a milestone invention in the field of microbiology. Several xylanolytic enzymes from mesophilic to extremophilic environments have been discovered by using metagenomic (functional and sequence-based) approaches (Verma and Satyanarayana, 2020). The CAZy database shows the presence of approximately 500 candidates of GH-10 and GH-11 xylanolytic enzymes using this approach to date, where the majority of them are uncharacterized. The share of the GH-10 metagenomic representative is almost four-fold as compared to the total count of GH-11 homologs. It indicates the wide distribution of GH-10 xylanases in the environment because these enzymes are less substrate-specific as compared to the GH-11 xylanases. The compost soil metagenome has come out with several hyperthermophilic endoxylanases that showed their optimum temperature beyond $65^{\circ} \mathrm{C}$ (Verma and Satyanarayana, 2020). For example, metagenomic endoxylanases XYL38 (Ellila et al., 2019), Mxyl (Verma et al., 2013b), and Xyn11 (Kanokratana et al., 2014) recovered from compost metagenome showed the optimum temperature at $80^{\circ} \mathrm{C}$. Other sources such as Arctic Mid-Ocean Ridge vent (Fredriksen et al., 2019), Lobios Hot Spring sediment (Knapik et al., 2019), and sugarcane bagasse (Kanokratana et al., 2014) also revealed endoxylanases of hyper-thermophilic nature by having optimum activity at $80^{\circ} \mathrm{C}$. The genomic walking PCR (GWPCR) approach uncovered an exceptionally hyperthermophilic GH-10 endoxylanase from a hot pool metagenome that exhibited an optimum temperature of $100^{\circ} \mathrm{C}$ under acidic conditions (Sunna and Bergquist, 2003). It was supposed to be a member of Thermotogales endoxylanases; however, its metagenome did not amplify any of their representatives. Of the other extremophilic endoxylanases, metagenomics has also revealed several endoxylanases of acidophilic characteristics that exhibited their optimum pH below 6.0 (Kwon et al., 2010; Wang et al., 2015; Kim et al., 2018; Fredriksen et al., 2019), where the majority of them belong to the GH-10 family. A handful alkaliphilic endoxylanases have also been identified using the nonconventional metagenomic approaches, where most of them exhibit their optimum $\mathrm{pH}$ at or near 8.0 (Hu et al., 2008; Thidarat et al., 2012; Ariaeenejad et al., 2019). Only one endoxylanase (Mxyl) showed its optimum activity at pH 9.0 (Verma et al., 2013b). Moreover, this xylanase was of high molecular weight ( $\sim 43 \mathrm{kDa})$; it was even classified into the GH-11 family due to their amino acid composition/hydrophobic cluster analysis and also represent the signature $\beta$-jelly-shaped structure of $\mathrm{GH}-11$ endoxylanases. Termite gut acts as a reservoir of plant-degrading bacteria; therefore, the termite gut metagenome has also been explored to harvest endoxylanases (Rashamuse et al., 2016; 
Liu et al., 2019; Romero Victorica et al., 2020). In a pioneer report, Brennan et al. (2004) reported three GH-8 endoxylanases and one GH-11 endoxylanase from termite gut metagenome that was thermophilic (Topt. $50^{\circ} \mathrm{C}$ ) under an acidic $\mathrm{pH}$ range of 5-6. Very similar endoxylanases (Topt. $50^{\circ} \mathrm{C}$; pH 5-6) have been reported from other termite gut metagenomes (Rashamuse et al., 2016; Liu et al., 2019; Romero Victorica et al., 2020). While Sheng et al. (2015) reported one cold-active xylanase (xynGH11-7) from the termite gut metagenome that exhibited optimum activity at $30^{\circ} \mathrm{C}$ under acidic conditions. The majority of the termite gut endoxylanases are acidic and thermophilic in nature which could be due to the acquired characteristics of the gut environments. In a recent investigation, the termite gut metagenome was explored to identify the inhabitant bacterial communities of the termite gut (Romero Victorica et al., 2020). The investigation revealed the presence of five dominant phyla (Firmicutes, Proteobacteria, Spirochaetes, Fibrobacteres, and Bacteroidetes) in the gut of the termites that usually engaged either amino acid (C. fulviceps; a grass-wood feeder) or carbohydrate ( $N$. aquilinus; a wood feeder) metabolism. The cattle rumen metagenome has also been extensively used for retrieving the extremophilic endoxylanases (Wang et al., 2015; Duque et al., 2018; Kim et al., 2018; Ariaeenejad et al., 2019). Interestingly, the majority of these xylanases showed their optimum temperature at $50^{\circ} \mathrm{C}$ under acidic (Duque et al., 2018; Kim et al., 2018; Ghadikolaei et al., 2019) as well as alkaliphilic (Ariaeenejad et al., 2019) conditions.

Functional screening of the metagenomic libraries is comparatively more common for identifying the desired clones over the shotgun sequencing-based approaches. However, shotgun-based approaches have also uncovered a few extremophilic endoxylanases (Ghadikolaei et al., 2019; Kumar et al., 2019). Shotgun sequencing of Kinema metagenome revealed several industrial enzymes including xylanase deacetylase and $\beta$-xylosidase deacetylase. Therefore, Kinema could be employed as a potential source of microbial enzymes used in food processing industries. The 454 pyrosequencing of camel rumen metagenome discovered an acidic and thermophilic GH endoxylanase (XylCMS) with an unusual high molecular weight of $46 \mathrm{kDa}$ (Ghadikolaei et al., 2019). This highly halophilic endoxylanase showed stimulation of $132 \%$ in the presence of $5 \mathrm{M} \mathrm{NaCl}$ concentration (Ghadikolaei et al., 2019). Analysis of a metagenomic data set from Arctic Mid-Ocean Ridge vent also unveiled a novel thermo-acidophilic endoxylanase (AMOR_GH10A) that showed its optimum activity at $80^{\circ} \mathrm{C}$ (Fredriksen et al., 2019). This bifunctional endoxylanase (AMOR_GH10A) exhibits binding affinity toward xylan as well as glycan (Fredriksen et al., 2019). Similarly, metagenomic xylanase (UX66) exhibiting exception features by having two carbohydrates and two catalytic domains (Zhao et al., 2010). Mesophilic endoxylanases and like enzymes are countless using the metagenomic approach. Although the reports through shotgun metagenomic approaches on endoxylanases are very less, the technique has huge potential to recover more xylanases. The major concern with these existing metagenomic endoxylanases is their employability in various applications. The majority of these xylanases have not been characterized for their applications under extreme conditions, which leaves a legitimate gap to claim their industrial suitability and needs to be characterized.

\section{MOLECULAR ATTRIBUTES TO IMPROVE EXTREMOPHILIC ENDOXYLANASES}

Several mechanisms have been laid down to further improve the characteristics of extremophilic xylanases. The majority of the reports discuss the thermostability of the xylanases that include amino acid composition, oligomerization, disulfide bridges, hydrogen bonds, hydrophobic interactions, and inclusion of aromatic amino acids. Several attempts have been made to understand the molecular insights of the extremophilic endoxylanases using protein engineering approaches.

Modular organization and oligomerization have been observed to be one of the major reasons for achieving thermostability among proteins/enzymes (Vieille and Zeikus, 2001). For example, xylanase (XynA) of T. maritima is organized into five domains, where domains N1 and N2 were found to be crucial for optimum thermostability (Winterhalter et al., 1995). Similar domains have been observed in thermostable xylanase of Thermoanaerobacterium saccharolyticum B6A-RI, where deletion of the N-terminal region lost the stability of the xylanase without affecting its catalytic behavior (Lee et al., 1993). The authors suggest that deletion of the N-terminal region may affect the tertiary structure of the xylanase that maintains the stability at the higher temperature.

Amino acid composition finds a significant role in stabilizing xylanases at higher temperatures. Multiple-sequence alignment of mesophilic xylanases with their thermophilic homologs revealed that arginine-rich surfaces contribute to improving the thermostability of the xylanases (Mrabet et al., 1992; Paes et al., 2012). Sriprang et al. (2006) improved the thermostability of thermophilic GH-11 xylanase by $18-20$-fold by replacing the surface serine and threonine residues with arginine. Similarly, four cumulative mutations of serine/threonine with arginine residues have significantly enhanced the thermostability of metagenomic xylanase at $90^{\circ} \mathrm{C}$ (Verma and Satyanarayana, 2013a). The introduction of at least five arginine residues in endoxylanase of Trichoderma reesei resulted in a shift in optimum temperature as well as $\mathrm{pH}$ (Turunen et al., 2002), while Ayadi et al. (2015) obtained significant improvement in thermostability by replacing serine with threonine residues. Molecular modeling revealed that such mutations (S80T and S149T) assisted in hydrogen bonding and exhibited a packing effect (Ayadi et al., 2015). Hydrogen bonding between S208-N205 and S210-A55 in GH-11 xylanase of Neocallimastix patriciarum contributed significantly to improve the thermostability at the higher temperature of $70^{\circ} \mathrm{C}$ (Han et al., 2017). A double mutant (S22E/N32D) of xylanase protein of B. subtilis revealed strong hydrogen bonding for the stabilization of the protein at the higher temperature (Alponti et al., 2016). Therefore, amino acid composition is crucial for enhancing the stability of proteins and enzymes. Few studies indicate that higher alanine content may play a role in the stabilization by making the protein more helical (Vieille and Zeikus, 2001). 
Disulfide bridges enhance the stability of proteins by reducing the entropy of the unfolded proteins. Several attempts have been successfully done to improve the thermostability of xylanases by introducing disulfide bonds (Gruber et al., 1998; Turunen et al., 2002; Yang et al., 2017). The half-life of mutated xylanase (Q162H/Q162Y, N11D, and N38E) was increased up to $100 \mathrm{~min}$ by introducing disulfide bonds (Turunen et al., 2002). Several such cases have been observed where disulfide bonds along with other favorable mutations improved the thermostability up to 5,000-fold (Xiong et al., 2004; He et al., 2019). Disulfide bonds and multiple-proline substitutions in acidic xylanase of Aspergillus sulphureus enhanced the thermostability by 22 fold at $60^{\circ} \mathrm{C}$ (Yang et al., 2017). The introduction of intraand intermolecular disulfide bonds in xylanase of B. circulans showed a significant improvement in thermostability without any alteration in enzymatic activity (Wakarchuk et al., 1994). Tatu et al. (1993) emphasized that the cleavage of disulfide bonds can reduce $25 \% \quad \beta$-sheet structure and thus play a significant role in maintaining structural integrity. X-ray crystallographic studies of thermophilic xylanases T. lanuginosus and their comparison with several mesophilic homologs revealed the presence of extra disulfide bonds and abundance of charged amino acids throughout the protein (Gruber et al., 1998). $\beta$-Elimination of disulfide bridges and cysteine oxidation participate in inhibition and stimulation of the enzyme activity, respectively. $\beta$-Mercaptoethanol $(\beta-\mathrm{ME})$ and dithiothreitol (DTT)-like compounds protect the oxidation of cysteine and therefore either sustain or stimulate the enzyme activity (Knob and Carmona, 2010), while DTT or $\beta$-ME has shown a significant reduction in xylanase activity in the presence of DTT or $\beta$-ME such as Mxyl (Verma et al., 2013b), XylB8 (Matteotti et al., 2012), and thermostable xylanase of Talaromyces thermophilus (Maalej et al., 2009). Such disruptions significantly alter the conformation of the structure required for the functionality of the enzyme (Knob and Carmona, 2010).

Hydrophobic or electrostatic interactions have also been reported to enhance the stability of the xylanases. Thermostable xylanase of Bacillus strain D3 was speculated to have thermostability even at a temperature of $75^{\circ} \mathrm{C}$ due to the hydrophobic interaction, as no cysteine residues were identified that can make them stable like the xylanase of B. circulans $(73 \%$ sequence identity) (Harris et al., 1997). The xylanase of Bacillus strain D3 has been studied for thermostabilization, where the presence of cysteine residue may be considered for the formation of disulfide bonds. Moreover, homology modeling revealed the abundance of aromatic amino acids on the surface of the protein that assists in the formation of hydrophobic clusters by which protein exhibited thermostability (Connerton et al., 1999). Hakulinen et al. (2003) also emphasized aromatic residues on the surfaces of the xylanases for improving thermostability. The GH-11 xylanase of Dictyoglomus thermophilum also shared a significant portion of polar residues along with a slightly extended C-terminal region for enhanced thermostability (McCarthy et al., 2000).

Similar mechanisms participate in deciding the optimum $\mathrm{pH}$ of xylanases to make them acidic or alkaline. Mamo et al. (2009) reported that Val169, Ile170, and Asp171 in the ambiance of acid/base catalytic grooves participate to cleave the xylan residues under alkaline conditions. Moreover, such alkaliphilic xylanases harbored the greater count of acidic residues over the neutral xylanases. In another interesting report, a single amino acid substitution (N35D) in xylanase (BCX) of B. circulans was found sufficient to shift the $\mathrm{pH}$ optimum toward a more acidic region (5.7-4.6) along with a $20 \%$ increase in enzymatic activity. Overall, the study concluded that Asp35 and Glu172 participate in the usual acid/base catalysis mechanism of the enzymes and follow the reverse protonation mechanism (Joshi et al., 2000). Two mutants (E135V and E135R) showed a shift toward alkaline $\mathrm{pH}$ by 0.5 and 1.0 units respectively in the GH-11 xylanase of Bacillus sp. SN5 (Bai et al., 2016). Structural analysis of these mutants revealed that mutation at the position E135 with valine and arginine residues reduced the overall negative charge on the surface and introduced the salt bridge in the eight-residue loop (Gln131-Pro-Ser-Ile-Glu135-Gly-Thr-Ala138) to improve the alkalophilicity of the enzyme. Substitution of arginine at the surface level has been reported in many xylanases to make the xylanase more alkaliphilic (Shirai et al., 1997; Umemoto et al., 2009). Therefore, a golden rule may be proposed that the surface of acidophilic xylanases is rich in acidic residues (Fushinobu et al., 1998; Collins et al., 2005) while alkaliphilic xylanases prefer positively charged amino acids on their surfaces (Shirai et al., 1997; Wu et al., 2020). Such information may be explored to alter the alkalophilicity or acidophilicity of xylanases by determining the overall ratio of acidic or basic amino acids on their surfaces.

Halophilic xylanases also exhibit a greater number of acidic residues on the surfaces of the xylanases (Warden et al., 2015). Wu et al. (2020) reported that halotolerant xylanase (AkXynC) comprised merely $2.73 \%$ of positively charged amino acids. Moreover, hydrophobic amino acids also contribute to making xylanase more halophilic (Oren, 2011).

The psychrophilic xylanases exhibit different mechanisms to show maximum activity under low temperature. Van Petegem et al. (2003) described that cold-active xylanases exhibit high flexibility and transformations at low energy costs. The crystal structure of cold-active xylanase (xyn8) from Pseudoalteromonas haloplanktis explained that a smaller number of salt bridges and abundance of hydrophobic residue could make an enzyme coldactive (Van Petegem et al., 2003). Zheng et al. (2016) also affirmed that the synergistic effect of a higher number of flexible loops, flexibility in substrate binding residues, and increased exposure of hydrophobic residues enhance the overall activity of coldactive xylanase.

\section{APPLICATIONS OF EXTREMOPHILIC XYLANASES}

Xylanases find applications in different industries such as bakery, paper, food, feed, oil extraction, textile, papad making, juice, biorefinery, prebiotic production, and pharmaceutical industries. By looking into the various steps of downstream processing of these industries, the raw material needs to be gone through several extreme conditions that may include higher temperature, alkaline/acidic conditions, high salt, or solvent-rich 
solutions. Therefore, the industries look for polyextremophilic endoxylanases that can tolerate such conditions.

\section{Paper Industry}

Thermo-alkali-stable xylanases facilitate the release of lignin from the pulp samples by loosening the multiple cross-linked xylan residues into the lignocellulosic biomass. This process occurs at very high temperatures under alkaline conditions; therefore, xylanases that exhibit stability at higher temperature and $\mathrm{pH}$ can perform better over the mesophilic homologs. Polyextremophilic xylanase of $B$. halodurans TSEV1 was successfully employed to bleach the paper pulp where a reduction of 2.42 units in kappa number was observed (Kumar and Satyanarayana, 2012). An alkali-tolerant xylanase of B. licheniformis 77-2 showed $\sim 30 \%$ reduction in chlorine consumption as compared to the control samples (Damiano et al., 2003). Thermo-alkali-stable metagenomic xylanase (Mxyl) also showed applicability in biobleaching of pulp samples where a $29 \%$ reduction of chlorine derivatives was observed to achieve an optimum brightness of the paper (Verma and Satyanarayana, 2013b). In an earlier report, the crude broth having thermophilic xylanase from B. coagulans was employed to reduce the kappa number by $5.45 \%$ of eucalyptus pulp samples (Choudhury et al., 2006). Similarly, a cocktail of thermostable xylanase and pectinase reduced the kappa number by $6.8 \%$ and thus reduce the chlorine consumption by $25 \%$ without compromising the brightness of the paper (Kaur et al., 2010). The thermophilic xylanases from B. halodurans C-125 (Lin et al., 2013) and B. stearothermophilus SDX (Garg et al., 2011) were also employed effectively in the bio-bleaching of wheat straw pulp samples. Thermo-alkali-stable xylanases not only reduce the release of chlorine and their derivatives from pulp samples during bio-bleaching but also decrease the dioxin formation that usually generates in a chemical reaction of chlorine and lignin compounds (Sharma et al., 2007). Dioxins are neurotoxic and persistent that exhibit the phenomenon of biomagnification and therefore induce pollution. Thermo-alkalistable xylanases facilitate the release of lignin from the pulp samples by loosening the multiple cross-linked xylan residues into the lignocellulosic biomass. This process occurs at very high temperatures under alkaline conditions; therefore, xylanases that exhibit stability at higher temperature and $\mathrm{pH}$ can perform better over the mesophilic homologs. Polyextremophilic xylanase of $B$. halodurans TSEV1 was successfully employed to bleach the paper pulp where a reduction of 2.42 units in kappa number was observed (Kumar and Satyanarayana, 2012). An alkalitolerant xylanase of $B$. licheniformis $77-2$ showed $\sim 30 \%$ reduction in chlorine consumption as compared to the control samples (Damiano et al., 2003). In an earlier report, the crude broth having thermophilic xylanase from $B$. coagulans was employed to reduce the kappa number by $5.45 \%$ of eucalyptus pulp samples (Choudhury et al., 2006). Similarly, a cocktail of thermostable xylanase and pectinase reduced the kappa number by $6.8 \%$ and thus reduce the chlorine consumption by $25 \%$ without compromising the brightness of the paper (Kaur et al., 2010). The thermophilic xylanases from B. halodurans C-125 (Lin et al., 2013) and Bacillus stearothermophilus SDX (Garg et al., 2011) were also employed effectively in the bio-bleaching of wheat straw pulp samples.

\section{Generation of Xylo-Oligosaccharides}

The use of thermophilic xylanases is also well documented for the generation of XOs from lignocellulosic biomass or agro residues. Hyperthermophilic xylanases of several Bacillus spp. (B. halodurnas, B. amyloliquefaciens, and $B$. halodurnas TSEV1) and Geobacillus spp. (G. thermoleovorans, G. thermodenitrificans TSAAI, and G. thermoleovorans AP07) have been successfully employed for the generation of XOs. The majority of these xylanases were endo-acting, therefore producing majorly xylobiose (XO2) along with a significant amount of XO3, XO4, and XO5 oligomers. Xylo-oligosaccharides find fabulous applications in prebiotics by modulating the gut microbiome for their betterment. Cold active halophilic xylanases of Glaceocola mesophila KMM 241 (Guo et al., 2009) and Sorangium cellulosum (Wang et al., 2012) can be better used for the generation of XOs. Thermophilic and psychrophilic xylanases not only exhibit the saccharification activity but also were able to minimize the possibility of microbial contamination during the process; therefore, they are considered superior over the mesophilic homologs.

\section{Bakery}

Xylanase treatment improves the quality of bread as it reduces the staling rate and increases the shelf-life (Liu et al., 2017; Passarinho et al., 2019). Staling causes significant financial loss to the baking industry. Loss of freshness in terms of lesser moisture increased crumb firmness, and decreased crumb elasticity corresponds to staling. Xylanases are usually incorporated before the baking of dough that assists in the conversion of insoluble hemicellulose into soluble sugars to enhance the sweetness and flavor. Xylanase treatment softens the dough, while softness is the result of arabinoxylan breakdown, which in turn releases water molecules (Oliveira et al., 2014). The development of a synergistic enzyme cocktail is an emerging trend in the baking industry for improved baking products. The selection of enzyme cocktails for the baking industry must be backed by rheological experiments, nutritional and chemical analyses, and baking trials (Almeida and Chang, 2012). In general, such cocktails comprise amylases, xylanases, and lipases exclusively for bread making (Katina et al., 2006). In a study where gluten-degrading enzymes were used along with polysaccharidehydrolyzing enzymes (amylases and xylanases), bread with better shape was obtained. The polysaccharide-degrading enzymes combine with crosslink-promoting enzymes (glucose oxidase and transglutaminase), an improvement in rheological properties and texture of the bread was recorded (Caballero et al., 2007). Combinations of xylanases and oxidases are used more often as they affect the structure and function of xylan. In some cases, the application of laccase and transglutaminase has also been reported in association with xylanases, where the laccase catalyzes dimerization of feruloylated esters in feruloylated arabinoxylans in the dough (Renzetti et al., 2010). Several studies have shown the successful utility of xylanolytic enzymes in enhancing the quality of the bread, individually or in synergism with 
other carbohydrases ( $\alpha$-amylase, glucanase, arabinofuranosidase, and laccase) (Flander et al., 2008). Trametes hirsuta xylanase and laccase were simultaneously applied on oat-wheat, which resulted in the dough's softness and an increase in dough volume. This significant improvement of the dough quality is the result of an increase in water content, soluble arabinoxylan, and other water-soluble polysaccharides (Oliveira et al., 2014). Enzyme cocktail of xylanase, $\beta$-xylosidase, $\alpha$-L-arabinofuranosidase, $\beta$-glucosidase, avicelase, $\alpha$-amylase, amyloglucosidase, CMCase, and protease was tested on water-insoluble arabinoxylan for their valuable impact in bread-making. This study showed a beneficial effect of using an enzyme cocktail for the baking industry to improve the quality of bread. Overall, it reduced the amylopectin retro-gradation by $17 \%$, while the crumb firmness was reduced by $25 \%$, and the wheat bread-specific volume increased by $22 \%$ (Oliveira et al., 2014). Studies are discussing the role of coldactive xylanases from different microorganisms (Dornez et al., 2011; Wang et al., 2012; Xu et al., 2014). In one such study, bread volume increased up to $28 \%$ when cold-active xylanases were used (Dornez et al., 2011). As compared to the mesophilic counterparts, cold-active enzymes display optimal activity at lower temperatures (Huston, 2008). Therefore, psychrophilic enzymes are in high demand in the baking industry, where dough mixing and proofing operate below $35^{\circ} \mathrm{C}$. Several investigations have shown the significant effect of low doses of psychrophilic xylanases to attain the maximal bread volume over the mesophilic xylanases (Dornez et al., 2011; Ma et al., 2018).

\section{Juice Industry}

The quality of fruits and vegetable juices can be determined by physically looking for turbidity in juices. For citrus fruits and other juices, turbidity acts as a quality indicator. Haze formation is another area of concern in the juice industry where hazy juice products are undesirable because of customer preferences. The haze consisted of insoluble multimolecular structures formed because of protein-polyphenol interactions (Rai et al., 2003; Pinelo et al., 2010). To remove undesired turbidity and haziness, plant cell wall-degrading enzymes can be employed. These enzymes include pectinolytic, cellulolytic, and hemicellulolytic enzymes. The application of plant cell wall-degrading enzymes results in quality products that appeal to manufacturers and consumers (Adiguzel et al., 2019; Suryawanshi et al., 2019). The use of xylanases for clarification and extraction of fruit juice is gaining momentum (Dhiman et al., 2011; Adiguzel et al., 2019). An alkali-thermophilic cellulase-free xylanase of Bacillus stearothermophilus showed potential application in the clarification of citrus juices (Dhiman et al., 2011). When xylanase was used for extraction and clarification of citrus fruit juice, there was a two-fold increase in reducing sugar content, while turbidity was reduced by $35.4 \%$ and a $53 \%$ increase was observed in the yield of fruit juice after its enzymatic treatment. The apple, sweet lime and pineapple, and pulp were also treated with the thermostable and acid-stable xylanase obtained from $B$. licheniformis to enhance their clarity by Bajaj and Manhas (2012). Treatment with xylanase results in a two-fold increase in the reducing sugar content in apple juice (750$1320 \mathrm{mg} / \mathrm{ml})$, pineapple juice $(375-700 \mathrm{mg} / \mathrm{ml})$, and lime juice
(300-620 mg/ml). Further, turbidity was reduced by $79 \%$ for apple, $70 \%$ for pineapple, and $76 \%$ for lime juice. Similarly, pineapple, apple, and tomato juices improved multifold when the purified xylanase obtained from Bacillus pumilus has been utilized (Nagar et al., 2013). This enzymatic treatment of pulp showed a reduction in turbidity and viscosity without affecting the acid neutrality and significant improvement in juice clarity. In another study, xylanase from Bacillus pumilus was used for tomato juice extraction and clarification (Nagar et al., 2012).

\section{Xylanases in Edible Oil Extraction}

Mechanical pressing yields lower oil, while solvent extraction using hexane is not environment friendly which prompted to the development of alternative edible oil extraction processes that permit high oil yield and are eco-friendly. The aqueous enzymatic extraction (AEE) process of oil is an environmentfriendly alternative process of vegetable oil extraction. Enzymeassisted pressing and total solubilization of the oil-bearing constituents have been used in AEE. Cellulases, hemicellulases, and pectinases are the most commonly used cell wall-degrading enzymes used in AEE. Enzyme-assisted pressing employs a mixture of cellulases and hemicellulases. Combinations of cellulases and hemicellulases are determined by the biochemical composition of the secondary cell walls, primary cell wall, and the oil storage cell organelle oleosomes. The cell wall of different oil feedstocks has a different biochemical composition of hemicelluloses and celluloses, organized in a complex structure. In the aqueous enzymatic extraction (AEE) process, water is used as a medium of oil extraction from the feedstock. AEE exploits the amphipathic property of lipid molecules. Watersoluble components of amphipathic lipid molecules interact with a water molecule to form an oil emulsion. This emulsified product from the AEE process is later de-emulsified using physical changes or by adding enzymes to the aqueous medium. It is imminent to know the plant cell wall constituents to be able to select the best enzymes for efficient and optimal oil yields. In the absence of enzymes, the AEE process gives a low oil yield ranging from 28 to $66 \%$. The application of enzymes in AEE enhances oil yield (Dickey et al., 2008). In a recently published study, it has been shown that ultrasonic-microwave-assisted aqueous enzymatic extraction (UMAAEE) can be a quick and environmentally friendly method for oil production from cherry seed oil as compared to the organic solvent extraction method (Hu et al., 2019). Cellulase, hemicellulase, and pectinase in 1:1:1 was used as an enzyme cocktail.

\section{Other Miscellaneous Applications of Extremophilic Endoxylanases}

Xylanases were also employed in wafer improvement. A single report discusses the application of xylanase for refining the quality of black gram-based papad (an Indian traditional wafer) (Awalgaonkar et al., 2015). The water requirement and hardness of dough were significantly reduced by adding $50 \mathrm{mg} / \mathrm{kg}$ xylanase into the prepared dough. The black gram contains substantial amount of arabinoxylan; xylanase-based hydrolysis of arabinoxylan also reduced the oil consumption at a significant level. 
Due to outstanding hydrolysis of xylanases and cellulases of lignocellulosic biomass (LCB), these enzymes have been successfully employed in biorefinery industries (Smith et al., 2017; Bhardwaj et al., 2019). Disintegration of complex LCB generates monomeric sugars that can be transformed into bioethanol using suitable microorganisms (Basit et al., 2018). Simultaneous scarification and fermentation of LCB in the presence of Geobacillus sp. DUSELR13 and Geobacillus thermoglucosidasius produced 3.53 and $3.72 \mathrm{~g} / \mathrm{l}$ ethanol from prairie cord grass and corn stover, respectively (Bibra et al., 2018). Yasuda et al. (2014) also reported a high yield of $74 \%$ ethanol by using the SSCF process in the presence of cellulase and xylanase. The majority of the reports suggest the pretreatment of the lignocellulosic biomass using either anhydrous ammonia, acetic acid, or steam to enhance the efficiency of xylanases and cellulases in saccharification (Yasuda et al., 2014; Bondesson and Galbe, 2016). For biorefinery, broad substrate specificity is usually recommended which is a characteristic feature of GH-10 xylanases; however, a report suggests that the xylooligosaccharides may inhibit cellulase and thus reduce the bioethanol yield (Kumar and Wyman, 2009; Qing et al., 2010). The GH-11 xylanases are therefore preferred that are xylan specific and release the sugars in a controlled manner (Henrissat and Davies, 1997; Qing et al., 2010). GH-11 xylanase (XYL10C- $\Delta \mathrm{N}$ ) supports this hypothesis that showed a synergistic effect with cellulose and generates the sugars by reducing the sugar-producing rate to reduce the xylan-induced obstacles (You et al., 2018). Partial utilization of LCB-generated sugars by native microorganisms is one of the limiting factors that could be overcome by developing recombinant strains that can transform the available sugar in an efficient manner (Aftab et al., 2018).

Xylitol is a reduced form of xylose and finds application in pharmaceutical industries especially in oral health. It is the chief constituent of several xylitol-based-chewing gums, toothpaste, and antidiabetic food supplements as a sweetening agent along with anti-cariogenic additive (Chattopadhyay et al., 2014; Rafiqul et al., 2014). In an earlier report, D-xylose sugars were achieved by treating wheat straw with acid and xylanase that yielded $7 \%$ xylitol of 99\% purity (Liavoga et al., 2007). Several such reports discuss the applicability of xylanase for xylitol production using microbial xylanases (Guo et al., 2013; Kalim et al., 2015; Sena et al., 2017). However, xylose exhibits significant inhibition on xylanase activity which may be up to $80 \%$ in the presence of $10 \%(\mathrm{w} / \mathrm{v})$ xylose. Therefore, xylitol production demands stringent conditions that also include thermostable xylanases during the chemo-catalytic hydrogenation process. A novel onepot cascade process yielded $80 \%$ xylitol in the presence of xylanase and ruthenium/carbon catalyst (Ayubi et al., 2021). The estimated market of xylitol is $\$ 740$ million which encourages the wide applications of thermophilic and barophilic endoxylanase to achieve highly valued chemical xylitol and improving the lignocellulose variolization.

\section{CONCLUSION}

The estimated global industrial enzyme market was approximately US\$ 5.6 billion during 2019, and it is projected to rise at a compound annual growth rate (CAGR) of $6.4 \%$ from 2020 to $2027,{ }^{2}$ where xylanolytic enzymes share a significant chunk of total carbohydrases. Therefore, more efforts should be made for presenting endoxylanases and like enzymes as an alternative to chemical and physical methods to make the environment eco-friendlier cost-effectively. The GH families (GH-5, GH-7, GH-8, GH-10, GH-11, GH-43, and GH-141) harbor several extremophilic xylanolytic enzymes of potential biotechnological applications. Extremophilic xylanases not only enhance the bioconversion of the lignocellulosic biomass into a valuable product but also reduce the possibilities of microbial contamination during the entire process. Bacterial endoxylanases may be considered as the better option for industrial applications over the eukaryotic sources because of their broad range of properties at extreme $\mathrm{pH}$ and temperatures. The existing archaeal endoxylanases exhibit hyperthermophilic properties; however, the majority of them are either acidic or neutral. Therefore, protein engineering approaches can be used for improving their alkalophilicity. Even directed evolution, site-directed mutagenesis, and DNA shuffling approaches may be considered for extending the half-life of several bacterial xylanases that exhibit their optimum temperature at or above $80^{\circ} \mathrm{C}$ but lose their stability at these temperatures for longer incubations. Metagenomic approaches have not been well explored to date for harnessing extremophilic endoxylanases that exhibit the potential to reveal novel candidates from extreme environments. Therefore, functional as well as shotgun-sequenced-based approaches can be employed for retrieving novel targets. Moreover, the microbiome analysis of the environmental samples should be assessed to go with a rational approach that may enhance the discovery of a novel target multifold by correlating their metabolic profiling with the inhabitant microorganisms of that environment. A significant effort should also be made to characterize the existing xylanolytic enzymes where their count is significantly high. Commercialization of endoxylanases needs to be boosted by emphasizing their unique characteristics to the industries as well as for the sake of the environment.

\section{AUTHOR CONTRIBUTIONS}

DV conceptualized and wrote the article.

\section{FUNDING}

I am grateful to the Frontiers Fee support system for providing the full waiver to this article.

\section{ACKNOWLEDGMENTS}

DV is thankful to Babasaheb Bhimrao Ambedkar University (BBAU), Lucknow, India, for providing the academic infrastructure and peaceful environment. DV highly thankful to Gautam Buddha Central Library, BBAU, Lucknow, for providing the access of several journals and other useful resources.

\footnotetext{
${ }^{2}$ www.grandviewresearch.com
} 


\section{REFERENCES}

Adamsen, A. K., Lindhagen, J., and Ahring, B. K. (1995). Optimization of extracellular xylanase production by Dictyoglomus sp. B1 in continuous culture. Appl. Microbiol. Biotechnol. 44, 327-332. doi: 10.1007/s002530050562

Adiguzel, G., Faiz, O., Sisecioglu, M., Sari, B., Baltaci, O., Akbulut, S., et al. (2019). A novel endo- $\beta$-1,4-xylanase from Pediococcus acidilactici GC25; Purification, characterization and application in clarification of fruit juices. Int. J. Biol. Macromol. 129, 571-578. doi: 10.1016/j.ijbiomac.2019.02.054

Aftab, M. N., Zafar, A., Iqbal, I., Kaleem, A., Zia, K. M., and Awan, A. R. (2018). Optimization of saccharification potential of recombinant xylanase from Bacillus licheniformis. Bioengineered 9, 159-165.

Akila, G., and Chandra, T. S. (2003). A novel cold-tolerant Clostridium strain PXYL1 isolated from a psychrophilic cattle manure digester that secretes thermolabile xylanase and cellulase. FEMS Microbiol. Lett. 219, 63-67. doi: 10.1016/s0378-1097(02)01196-5

Almeida, E. L., and Chang, Y. K. (2012). Effect of the addition of enzymes on the quality of frozen pre-baked French bread substituted with whole wheat flour. LWT Food Sci. Technol. 49, 64-72. doi: 10.1016/j.lwt.2012.04.019

Alponti, J. S., Fonseca Maldonado, R., and Ward, R. J. (2016). Thermostabilization of Bacillus subtilis GH-11 xylanase by surface charge engineering. Inter. J. Biol. Macromol. 87, 522-528. doi: 10.1016/j.ijbiomac.2016.03.003

Amann, R. I., Ludwig, W., and Schleifer, K. (1995). Phylogenetic identification and in situ detection of individual microbial cells without cultivation. Microb. Rev. 59, 143-169. doi: 10.1128/mmbr.59.1.143-169.1995

Amel, B. D., Nawel, B., Khelifa, B., Mohammed, G., Manon, J., Salima, K. G., et al. (2016). Characterization of a purified thermostable xylanase from Caldicoprobacter algeriensis sp. nov. strain TH7C1T. Carbohydr. Res. 419, 60-68. doi: 10.1016/j.carres.2015.10.013

Amoozegar, M. A., Safarpour, A., Noghabi, K. A., Bakhtiary, T., and Ventosa, A. (2019). Halophiles and their vast potential in biofuel production. Front. Microbiol. 10:1895. doi: 10.3389/fmicb.2019.01895

An, J., Xie, Y., Zhang, Y., Tian, D., Wang, S., Yang, G., et al. (2015). Characterization of a thermostable, specific GH10 xylanase from Caldicellulosiruptor bescii with high catalytic activity. J. Mol. Catal. B Enzym. 117, 13-20. doi: 10.1016/j. molcatb.2015.04.003

Anbarasan, S., Wahlström, R., Hummel, M., Ojamo, H., Sixta, H., and Turunen, O. (2017). High stability and low competitive inhibition of thermophilic Thermopolyspora flexuosa GH-10 xylanase in biomass-dissolving ionic liquids. Appl. Microb. Biotechnol. 101, 1487-1498. doi: 10.1007/s00253-016-7922-9

Andrade, C. M., Aguiar, W. B., and Antranikian, G. (2001). Physiological aspects involved in production of xylanolytic enzymes by deep-sea hyperthermophilic archaeon Pyrodictium abyssi. Appl. Biochem. Biotechnol. 91, 655-669. doi: 10.1385/abab:91-93:1-9:655

Annamalai, N., Thavasi, R., Jayalakshmi, S., and Balasubramanian, T. (2009). Thermostable and alkaline tolerant xylanase production by Bacillus subtilis isolated form marine environment. Ind. J. Biotechnol. 8, 291-297.

Archana, A., and Satyanarayana, T. (1998). Cellulase-free xylanase production by thermophilic Bacillus licheniformis A99. Ind. J. Microbiol. 38, 13-19.

Ariaeenejad, S., Hosseini, E., Maleki, M., Kavousi, K., Moosavi-Movahedi, A. A., and Salekdeh, G. H. (2019). Identification and characterization of a novel thermostable xylanase from camel rumen metagenome. Int. J. Biol. Macromol. 126, 1295-1302. doi: 10.1016/j.ijbiomac.2018.12.041

Awalgaonkar, G., Sarkar, S., Bankar, S., and Singhal, R. S. (2015). Xylanase as a processing aid for papads, an Indian traditional food based on black gram. $L W T$ Food Sci. Technol. 62, 1148-1153.

Ayadi, D. Z., Sayari, A. H., Hlima, H. B., Mabrouk, S. B., Mezghani, M., and Bejar, S. (2015). Improvement of Trichoderma reesei xylanase II thermal stability by serine to threonine surface mutations. Int. J. Biol. Macromol. 72, 163-170. doi: 10.1016/j.ijbiomac.2014.08.014

Ayubi, M. M., Werner, A., Steudler, S., Haase, S., Lange, R., Walther, T., et al. (2021). Enhanced xylan conversion to xylitol in a bio- and chemocatalytic one-pot process. Catal. Today 367, 137-144. doi: 10.1016/j.cattod. 2020.06.009

Bai, W., Cao, Y., Liu, J., Wang, Q., and Jia, Z. (2016). Improvement of alkalophilicity of an alkaline xylanase Xyn11A-LC from Bacillus sp. SN5 by random mutation and Glu135 saturation mutagenesis. BMC Biotechnol. 16:77. doi: 10.1186/s12896-016-0310-9
Bajaj, B. K., and Manhas, K. (2012). Production and characterization of xylanase from Bacillus licheniformis $\mathrm{P} 11(\mathrm{C})$ with potential for fruit juice and bakery industry. Biocatal. Agric. Biotechnol. 1, 330-337. doi: 10.1016/j.bcab.2012.07. 003

Bajaj, B. K., and Singh, N. P. (2010). Production of xylanase from an alkalitolerant Streptomyces sp. $7 \mathrm{~b}$ under solid-state fermentation, its purification, and characterization. Appl. Biochem. Biotechnol. 162, 1804-1818. doi: 10.1007/ s12010-010-8960-x

Basit, A., Liu, J., Rahim, K., Jiang, W., and Lou, H. (2018). Thermophilic xylanases: from bench to bottle. Crit. Rev. Biotechnol. 38, 989-1002. doi: 10.1080/ 07388551.2018.1425662

Bhalla, A., Bischoff, K. M., and Sani, R. K. (2015). Highly thermostable xylanase production from a thermophilic Geobacillus sp. strain WSUCF1 utilizing lignocellulosic biomass. Front. Bioeng. Biotechnol. 3:84. doi: 10.3389/fbioe.2015. 00084

Bhalla, A., Bischoff, K. M., Uppugundla, N., Balan, V., and Sani, R. K. (2014). Novel thermostable endo-xylanase cloned and expressed from bacterium Geobacillus sp. WSUCF1. Bioresour. Technol. 165, 314-318. doi: 10.1016/j.biortech.2014. 03.112

Bhardwaj, N., Kumar, B., and Verma, P. (2019). A detailed overview of xylanases: an emerging biomolecule for current and future prospective. Bioresour. Bioprocess. 6:40.

Bibi, Z., Ul Qader, S. A., Aman, A., Ur Rehman, H., Nawaz, M. A., Karim, A., et al. (2018). Xylan deterioration approach: purification and catalytic behavior optimization of a novel $\beta$-1,4-d-xylanohydrolase from Geobacillus stearothermophilus KIBGE-IB29. Biotechnol. Rep. 21:e00299.

Bibra, M., Kunreddy, V. R., and Sani, R. K. (2018). Thermostable xylanase production by Geobacillus sp. Strain DUSELR13, and its application in ethanol production with lignocellulosic biomass. Microorganisms 6:93. doi: 10.3390/ microorganisms6030093

Bocchini, D. A., Alves-Prado, H. F., Baida, L. C., Roberts, I. C., Gomes, E., and Da-Silva, R. (2002). Optimization of xylanase production by Bacillus circulans D1 in submerged fermentation using RSM. Process. Biochem. 38, 727-773. doi: 10.1016/s0032-9592(02)00207-8

Bocchini, D. A., Gomes, E., and Da Silva, R. (2008). Xylanase production by Bacillus circulans D1 using maltose as carbon source. Appl. Biochem. Biotechnol. 146, 29-37. doi: 10.1007/s12010-007-8051-9

Bok, J. D., Goers, S. K., and Eveleigh, D. E. (1994). Cellulase and xylanase systems of Thermotoga neapolitana. ACS Symp. Ser. 566, 54-65. doi: 10.1021/bk-19940566.ch002

Bondesson, P. M., and Galbe, M. (2016). Process design of SSCF for ethanol production from steam-pre-treated, acetic-acid-impregnated wheat straw. Biotechnol. Biofuels 9:222. doi: 10.1186/s13068-016-0635-6

Bragger, J. M., Daniel, R. M., Coolbear, T., and Morgan, H. W. (1989). Very stable enzymes from extremely thermophilic archaebacteria and eubacteria. Appl. Microbiol. Biotechnol. 31, 556-561. doi: 10.1007/bf00270794

Breccia, J. D., Siñeriz, F., Baigorí, M. D., Castro, G. R., and Hatti-Kaul, R. (1998). Purification and characterization of a thermostable xylanase from Bacillus amyloliquefaciens. Enzyme Microb. Technol. 22, 42-49. doi: 10.1016/s01410229(97)00102-6

Brennan, Y. L., Callen, W. N., Christoffersen, L., Dupree, P., Goubet, F., Healey, S., et al. (2004). Unusual microbial xylanases from insect guts. Appl. Environ. Microbiol. 70, 3609-3617. doi: 10.1128/aem.70.6.3609-3617.2004

Caballero, P. A., Gomez, M., and Rosell, C. M. (2007). Improvement of dough rheology, bread quality and bread shelf-life by enzymes combination. J. Food Eng. 81, 42-53. doi: 10.1016/j.jfoodeng.2006.10.007

Cabrera, M. Á, and Blamey, J. M. (2018). Biotechnological applications of archaeal enzymes from extreme environments. Biol. Res. 51:37.

Cannio, R., Di Prizito, N., Rossi, M., and Morana, A. (2004). A xylan-degrading strain of Sulfolobus solfataricus: isolation and characterization of the xylanase activity. Extremophiles 8, 117-124. doi: 10.1007/s00792-003-0370-3

Chaiyaso, T., Kuntiya, A., Techapun, C., Leksawasdi, N., Seesuriyachan, P., and Hanmoungjai, P. (2011). Optimization of cellulase-free xylanase production by thermophilic Streptomyces thermovulgaris TISTR1948 through plackettburman and response surface methodological approaches. Biosci. Biotechnol. Biochem. 75, 531-537. doi: 10.1271/bbb.100756

Chakdar, H., Kumar, M., Pandiyan, K., Singh, A., Nanjappan, K., Kashyap, P. L., et al. (2016). Bacterial xylanases: biology to biotechnology. 3 Biotech 6:150. 
Chang, W. S., Tsai, C. L., and Tseng, M. J. (2004). Cloning and characterization of two thermostable xylanases from an alkaliphilic Bacillus firmus. Biochem. Biophys. Res. Commun. 319, 1017-1025. doi: 10.1016/j.bbrc.2004.05.078

Chattopadhyay, S., Raychaudhuri, U., and Chakraborty, R. (2014). Artificial sweeteners - A review. J. Food Sci. Technol. 51, 611-621.

Chen, S., Kaufman, M. G., Miazgowicz, K. L., Bagdasarian, M., and Walker, E. D. (2013). Molecular characterization of a cold-active recombinant xylanase from Flavobacterium johnsoniae and its applicability in xylan hydrolysis. Bioresour. Technol. 128, 145-155. doi: 10.1016/j.biortech.2012.10.087

Choudhury, B., Chauhan, S., Singh, S., and Ghosh, P. (2006). Production of xylanase of Bacillus coagulans and its bleaching potential. World J. Microbiol. Biotechnol. 22, 283-288. doi: 10.1007/s11274-005-9033-0

Collins, T., Gerday, C., and Feller, G. (2005). Xylanases, xylanase families and extremophilic xylanases. FEMS Microbiol. Rev. 29, 3-23. doi: 10.1016/j.femsre. 2004.06.005

Collins, T., Hoyoux, A., Dutron, A., Georis, J., Genot, B., Dauvrin, T., et al. (2006). Use of glycoside hydrolase family 8 xylanases in baking. J. Cereal Sci. 43, 79-84. doi: $10.1016 /$ j.jcs.2005.08.002

Connerton, I., Cummings, N., Harris, G. W., Debeire, P., and Breton, C. (1999). A single domain thermophilic xylanase can bind insoluble xylan: evidence for surface aromatic clusters. Biochim. Biophys. Acta 11433, 110-121. doi: 10.1016/ s0167-4838(99)00151-x

Cordeiro, C. A. M., Martins, M. L. L., Luciano, A. B., and Da Silva, R. F. (2002). Production and properties of xylanase from thermophilic Bacillus sp. Braz. Arch. Biol. Technol. 45, 413-418.

Dahlberg, L., Holst, O., and Kristjansson, J. K. (1993). Thermostable xylanolytic enzymes from Rhodothermus marinus grown on xylan. Appl. Microbiol. Biotechnol. 40, 63-68.

Damiano, V. B., Bocchini, D. A., Gomes, E., and Da Silva, R. (2003). Application of crude xylanase from Bacillus licheniformis 77-2 to the bleaching of eucalyptus Kraft pulp. World J. Microbiol. Biotech. 19, 139-144.

Dheeran, P., Nandhagopal, N., Kumar, S., Jaiswal, Y. K., and Adhikari, D. K. (2012). A novel thermostable xylanase of Paenibacillus macerans IIPSP3 isolated from the termite gut. J. Ind. Microbiol. Biotechnol. 39, 851-860.

Dhiman, S. S., Garg, G., Sharma, J., and Mahajan, R. (2011). Characterization of statistically produced xylanase for enrichment of fruit juice clarification process. N. Biotechnol. 28, 746-755. doi: 10.1016/j.nbt.2010.11.004

Dhiman, S. S., Sharma, J., and Battan, B. (2008). Pre-treatment processing of fabrics by alkalo- thermophilic xylanase from Bacillus stearothermophilus SDX. Enzyme Microb. Technol. 43, 262-269. doi: 10.1016/j.enzmictec.2008.03.016

Dickey, L. C., Kurantz, M. J., and Parris, N. (2008). Oil separation from wetmilled corn germ dispersions by aqueous oil extraction and aqueous enzymatic oil extraction. Ind. Crops Prod. 27, 303-307. doi: 10.1016/j.indcrop.2007. 11.006

Dornez, E., Verjans, P., Arnaut, F., Delcour, J. A., and Courtin, C. M. (2011). Use of psychrophilic xylanases provides insight into the xylanase functionality in bread making. J. Agric. Food Chem. 59, 9553-9562.

Duque, E., Daddaoua, A., Cordero, B. F., Udaondo, Z., Molina-Santiago, C., Roca, A., et al. (2018). Ruminal metagenomic libraries as a source of relevant hemicellulolytic enzymes for biofuel production. Microb. Biotechnol. 11, 781787. doi: 10.1111/1751-7915.13269

Ellila, S., Bromann, P., and Nyyssonen, M. (2019). Cloning of novel bacterial xylanases from lignocellulose-enriched compost metagenomic libraries. $A M B$ Express 9:124.

Enkhbaatar, B., Lee, C. R., Hong, Y. S., and Hong, S. (2016). Molecular characterization of xylobiose- and xylopentaose-producing $\beta$-1,4-endoxylanase SCO5931 from Streptomyces coelicolor A3(2). Appl. Biochem. Biotechnol. 180, 349-360. doi: 10.1007/s12010-016-2103-y

Ferrer, M., Martínez-Abarca, F., and Golyshin, P. N. (2005). Mining genomes and 'metagenomes' for novel catalysts. Curr. Opin. Biotechnol. 16, 588-593. doi: 10.1016/j.copbio.2005.09.001

Flander, L., Rouau, X., Morel, M. H., Autio, K., Seppänen-Laakso, T., Kruus, K., et al. (2008). Effects of laccase and xylanase on the chemical and rheological properties of oat and wheat doughs. J. Agric. Food Chem. 56, 5732-5742.

Fredriksen, L., Stokke, R., Jensen, M. S., Westereng, B., Jameson, J. K., Steen, I., et al. (2019). Discovery of a thermostable GH10 xylanase with broad substrate specificity from the Arctic Mid-Ocean Ridge vent system. Appl. Environ. Microbiol. 85:e02970-18.
Fushinobu, S., Ito, K., Konno, M., Wakagi, T., and Matsuzawa, H. (1998). Crystallographic and mutational analyses of an extremely acidophilic and acidstable xylanase: biased distribution of acidic residues and importance of Asp37 for catalysis at low pH. Protein Eng. 11, 1121-1128. doi: 10.1093/protein/11.12. 1121

Garg, G., Dhiman, S. S., Mahajan, R., Kaur, A., and Sharma, J. (2011). Bleachboosting effect of crude xylanase from Bacillus stearothermophilus SDX on wheat straw pulp. N. Biotechnol. 28, 58-64. doi: 10.1016/j.nbt.2010.07.020

Gavrilov, S. N., Stracke, C., Jensen, K., Menzel, P., Kallnik, V., Slesarev, A., et al. (2016). Isolation and characterization of the first xylanolytic hyperthermophilic euryarchaeon Thermococcus sp. Strain 2319x1 and its unusual multidomain glycosidase. Front. Microbiol. 7:552. doi: 10.3389/fmicb.2016.00552

Geetha, K., and Gunasekaran, P. (2017). Purification of endoxylanase from Bacillus pumilus B20 for production of prebiotic xylo-oligosaccharide syrup: an in vitro study. Iran. J. Biotechnol. 15, 232-240. doi: 10.15171/ijb.1494

Ghadikolaei, K. K., Sangachini, E. D., Vahdatirad, V., Noghabi, K. A., and Zahiri, H. S. (2019). An extreme halophilic xylanase from camel rumen metagenome with elevated catalytic activity in high salt concentrations. AMB Express 9:86.

Ghosh, A., Sutradhar, S., and Baishya, D. (2019). Delineating thermophilic xylanase from Bacillus licheniformis DM5 towards its potential application in xylooligosaccharides production. World J. Microbiol. Biotechnol. 35:34.

Graciano, L., Corrêa, J. M., Vieira, F. G. N., Bosetto, A., Loth, E. A., Kadowaki, M. K., et al. (2015). Cloning and expression of the Xynal gene encoding a xylanase of the gh10 group in Caulobacter crescentus. Appl. Biochem. Biotechnol. 175, 3915-3929. doi: 10.1007/s12010-015-1560-Z

Gruber, K., Klintschar, G., Hayn, M., Schlacher, A., Steiner, W., and Kratky, C. (1998). Thermophilic xylanase from Thermomyces lanuginosus: high-resolution X-ray structure and modeling studies. Biochemistry 37, 13475-13485. doi: 10.1021/bi980864l

Guo, B., Chen, X. L., Sun, C. L., Zhou, B. C., and Zhang, Y. Z. (2009). Gene cloning, expression and characterization of a new cold-active and salt tolerant endoß-1,4-xylanase from marine Glaciecola mesophila KMM 241. Appl. Microbiol. Biotechnol. 84, 1107-1115. doi: 10.1007/s00253-009-2056-y

Guo, X., Zhang, R., Li, Z., Dai, D., Li, C., and Zhou, X. (2013). A novel pathway construction in Candida tropicalis for direct xylitol conversion from corncob xylan. Bioresour. Technol. 128, 547-552. doi: 10.1016/j.biortech.2012.10.155

Gupta, S., Bhushan, B., and Hoondal, G. S. (2000). Isolation, purification and characterization of xylanase from Staphylococcus sp. SG-13 and its application in bio-bleaching of kraft pulp. J. Appl. Microbiol. 88, 325-334. doi: 10.1046/j. 1365-2672.2000.00974.x

Gupta, V., Garg, S., Capalash, N., Gupta, N., and Sharma, P. (2015). Production of thermo-alkali-stable laccase and xylanase by co-culturing of Bacillus sp. and B. halodurans for biobleaching of kraft pulp and deinking of waste paper. Bioprocess. Biosyst. Eng. 38, 947-956. doi: 10.1007/s00449-014-1340-0

Hakulinen, N., Turunen, O., Jänis, J., Leisola, M., and Rouvinen, J. (2003). Threedimensional structures of thermophilic beta-1,4-xylanases from Chaetomium thermophilum and Nonomuraea flexuosa. Comparison of twelve xylanases in relation to their thermal stability. Eur. J. Biochem. 270, 1399-1412. doi: 10.1046/ j.1432-1033.2003.03496.x

Hamid, A., and Aftab, M. N. (2019). Cloning, purification, and characterization of recombinant thermostable $\beta$-Xylanase Tnap_0700 from Thermotoga naphthophila. Appl. Biochem. Biotechnol. 189, 1274-1290. doi: 10.1007/s12010019-03068-0

Han, N., Miao, H., Ding, J., Li, J., Mu, Y., Zhou, J., et al. (2017). Improving the thermostability of a fungal GH11 xylanase via site-directed mutagenesis guided by sequence and structural analysis. Biotechnol. Biofuels 10:133.

Handelsman, J. (2004). Metagenomics: application of genomics to uncultured microorganisms. Microbiol. Mol. Biol. Rev. 68, 669-685. doi: 10.1128/mmbr. 68.4.669-685.2004

Harris, G. W., Pickersgill, R. W., Connerton, I., Debeire, P., Touzel, J. P., Breton, C., et al. (1997). Structural basis of the properties of an industrially relevant thermophilic xylanase. Proteins 29, 77-86. doi: 10.1002/(sici)10970134(199709)29:1<77::aid-prot6>3.0.co;2-c

He, J., Tang, F., Chen, D., Yu, B., Luo, Y., Zheng, P., et al. (2019). Design, expression and functional characterization of a thermostable xylanase from Trichoderma reesei. PLoS One 14:e0210548. doi: 10.1371/journal.pone.0210548

Heinze, S., Mechelke, M., Kornberger, P., Liebl, W., Schwarz, W., and Zverlov, V. (2017). Identification of endoxylanase XynE from Clostridium thermocellum as the first xylanase of glycoside hydrolase family GH141. Sci. Rep. 7:11178. 
Henrissat, B., and Davies, G. (1997). Structural and sequence-based classification of glycoside hydrolases. Curr. Opin. Struct. Biol. 7, 637-644. doi: 10.1016/s0959$440 \mathrm{x}(97) 80072-3$

Hu, B., Wang, H., He, L., Li, Y., Li, C., and Zhang, Z. (2019). A method for extracting oil from cherry seed by ultrasonic-microwave assisted aqueous enzymatic process and evaluation of its quality. J. Chromatogr. A 1587, 50-60. doi: $10.1016 /$ j.chroma.2018.12.027

Hu, Y., Zhang, G., Li, A., Chen, J., and Ma, L. (2008). Cloning and enzymatic characterization of a xylanase gene from a soil-derived metagenomic library with an efficient approach. Appl. Microbiol. Biotechnol. 80, 823-830.

Huber, R., Dyba, D., Huber, H., Burggraf, S., and Rachel, R. (1998). Sulfur-inhibited Thermosphaera aggregans sp. nov., a new genus of hyperthermophilic archaea isolated after its prediction from environmentally derived $16 \mathrm{~S}$ rRNA sequences. Int. J. Syst. Bacteriol. 48, 31-38. doi: 10.1099/00207713-48-1-31

Hung, K.-S., Liu, S. M., Tzou, W. S., Lin, F. P., and Pan, C. L. (2011). Characterization of a novel GH10 thermostable, halophilic xylanase from the marine bacterium Thermoanaerobacterium saccharolyticum NTOU1. Process Biochem. 46, 1257-1263. doi: 10.1016/j.procbio.2011.02.009

Huston, A. L. (2008). "Biotechnological aspects of cold-adapted enzymes," in Psychrophiles: From Biodiversity to Biotechnology, eds R. Margesin, F. Schinner, J. C. Marx, and C. Gerday (Berlin: Springer), 347-363. doi: 10.1007/978-3-54074335-4_20

Hwang, I. T., Lim, H. K., Song, H. Y., Cho, S. J., Chang, J. S., and Park, N. J. (2010). Cloning and characterization of a xylanase, KRICT PX1 from the strain Paenibacillus sp. HPL-001. Biotechnol. Adv. 28, 594-601. doi: 10.1016/ j.biotechadv.2010.05.007

Ikram, U. H., Hussain, Z., Khan, M. A., Muneer, B., Afzal, S., Majeed, S., et al. (2012). Kinetic and thermodynamic study of cloned thermostable endo-1,4$\beta$ xylanase from Thermotoga petrophila in mesophilic host. Mol. Biol. Rep. 39, 7251-7261. doi: 10.1007/s11033-012-1555-6

Irfan, M., Gonzalez, C. F., Raza, S., Rafiq, M., Hasan, F., Khan, S., et al. (2018). Improvement in thermostability of xylanase from Geobacillus thermodenitrificans C5 by site directed mutagenesis. Enzyme Microb. Technol. 111, 38-47. doi: 10.1016/j.enzmictec.2018.01.004

Irfan, M., Kiran, J., Ayubi, S., Ullah, A., Rana, Q. U. A., Khan, S., et al. (2020). Immobilization of $\beta-1,4$-xylanase isolated from Bacillus licheniformis S3. J. Basic Microbiol. 60, 600-612. doi: 10.1002/jobm.202000077

Irfan, M., Nadeem, M., and Syed, Q. (2013). Purification and kinetics study of thermostable cellulase free xylanase from Bacillus subtilis. Protein Pept. Lett. 20, 1225-1231. doi: 10.2174/09298665113209990007

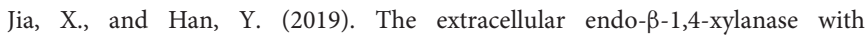
multidomain from the extreme thermophile Caldicellulosiruptor lactoaceticus is specific for insoluble xylan degradation. Biotechnol. Biofuels $12: 143$.

Jia, X., Mi, S., Wang, J., Qiao, W., Peng, X., and Han, Y. (2014). Insight into glycoside hydrolases for debranched xylan degradation from extremely thermophilic bacterium Caldicellulosiruptor lactoaceticus. PLoS One 9:e106482. doi: 10.1371 /journal.pone. 0106482

Joshi, M. D., Sidhu, G., Pot, I., Brayer, G. D., Withers, S. G., and McIntosh, L. P. (2000). Hydrogen bonding and catalysis: a novel explanation for how a single amino acid substitution can change the $\mathrm{pH}$ optimum of a glycosidase. J. Mol. Biol. 299, 255-279. doi: 10.1006/jmbi.2000.3722

Kalim, B., Böhringer, N., Ali, N., and Schäberle, T. F. (2015). Xylanases-from microbial origin to industrial application. Biotechnol. J. Int. 7, 1-20. doi: 10. 9734/bbj/2015/15982

Kamble, R. D., and Jadhav, A. R. (2012). Isolation, purification, and characterization of xylanase produced by a new species of Bacillus in solid state fermentation. Int. J. Microbiol. 2012:683193.

Kanokratana, P., Eurwilaichitr, L., Pootanakit, K., and Champreda, V. (2014). Identification of glycosyl hydrolases from a metagenomic library of microflora in sugarcane bagasse collection site and their cooperative action on cellulose degradation. J. Biosci. Bioeng. 119, 384-391. doi: 10.1016/j.jbiosc.2014.09.010

Kapoor, M., Nair, L. M., and Chander, K. R. (2008). Cost-effective xylanase production from free and immobilized Bacillus pumilus strain MK001 and its application in saccharification of Prosopis juliflora. Biochem. Eng. J. 38, 88-97. doi: 10.1016/j.bej.2007.06.009
Katina, K., Salmenkallio-Marttila, M., Partanen, R., Forssell, P., and Autio, K. (2006). Effects of sourdough and enzymes on staling of high-fibre wheat bread. Food Sci. Technol. 39, 479-491. doi: 10.1016/j.lwt.2005.03.013

Kaur, A., Mahajan, R., Singh, A., Garg, G., and Sharma, J. (2010). Application of cellulase-free xylano-pectinolytic enzymes from the same bacterial isolate in bio-bleaching of kraft pulp. Bioresour. Technol. 101, 9150-9155. doi: 10.1016/ j.biortech.2010.07.020

Khandeparkar, R. D. S., and Bhosle, N. B. (2006). Isolation, purification and characterization of the xylanase produced by Arthrobacter sp. MTCC 5214 when grown in solid state fermentation. Enzyme Microb. Technol. 39, 732-742. doi: 10.1016/j.enzmictec.2005.12.008

Khandeparker, R., Verma, P., and Deobagkar, D. (2011). A novel halotolerant xylanase from marine isolate Bacillus subtilis $\mathrm{CHO} 40$, gene cloning and sequencing. N. Biotechnol. 28, 814-821. doi: 10.1016/j.nbt.2011.08.001

Kiddinamoorthy, J., Anceno, A. J., Haki, G. D., and Rakshit, S. K. (2008). Production, purification and characterization of Bacillus sp. GRE7 xylanase and its application in eucalyptus kraft pulp bio-bleaching. World J. Microbiol. Biotechnol. 24, 605-612. doi: 10.1007/s11274-007-9516-2

Kim, D. Y., Shin, D. H., Jung, S., Lee, J. S., Cho, H.-Y., Bae, K. S., et al. (2014). Biocatalytic properties and substrate-binding ability of a modular GH10 $\beta-1,4-$ xylanase from an insect-symbiotic bacterium, Streptomyces mexicanus HY-14. J. Microbiol. 52, 863-870. doi: 10.1007/s12275-014-4390-8

Kim, H. B., Leeb, K. T., Kim, M. J., Lee, J. S., and Kim, K. S. (2018). Identification and characterization of a novel KG42 xylanase (GH-10 family) isolated from the black goat rumen-derived metagenomic library. Carbohydr. Res. 469, 1-9. doi: 10.1016/j.carres.2018.08.010

Kim, S. K., Chung, D., Himmel, M. E., Bomble, Y., and Westpheling, J. (2016). Heterologous expression of family 10 xylanases from Acidothermus cellulolyticus enhances the exoproteome of Caldicellulosiruptor bescii and growth on xylan substrates. Biotechnol. Biofuels 9:176.

Knapik, K., Becerra, M., and Gonzqlez-Siso, M. (2019). Microbial diversity analysis and screening for novel xylanase enzymes from the sediment of the Lobios Hot Spring in Spain. Sci. Rep. 9:11195.

Knob, A., and Carmona, E. C. (2010). Purification and characterization of two extracellular xylanases from Penicillium sclerotiorum: a novel acidophilic xylanase. Appl. Biochem. Biotechnol. 162, 429-443. doi: 10.1007/s12010-0098731-8

Ko, C. H., Tsai, C. H., Tu, J., Lee, H. Y., Ku, L. T., Kuo, P., et al. (2010). Molecular cloning and characterization of a novel thermostable xylanase from Paenibacillus campinasensis BL11. Process Biochem. 45, 1638-1644. doi: 10. 1016/j.procbio.2010.06.015

Ko, J. K., Ko, H., Kim, K. H., and Choi, I. G. (2016). Characterization of the biochemical properties of recombinant Xyn10C from a marine bacterium, Saccharophagus degradans 2-40. Bioprocess Biosyst. Eng. 39, 677-684. doi: 10.1007/s00449-016-1548-2

Kohilu, U., Nigam, P., Singh, D., and Chaudhary, K. (2001). Thermostable, alkaliphilic and cellulase free xylanases production by Thermoactinomyces thalophilus subgroup C. Enzyme Microb. Technol. 28, 606-610. doi: 10.1016/ s0141-0229(01)00320-9

Kublanov, I. V., Bidjieva, S. K. H., Mardanov, A. V., and BonchOsmolovskaya, E. A. (2009). Desulfurococcus kamchatkensis sp. nov., A novel hyperthermophilic protein-degrading archaeon isolated from a Kamchatka hot spring. Int. J. Syst. Evol. Microbiol. 59, 1743-1747. doi: 10.1099/ijs.0.006726-0

Kumar, J., Sharma, N., Kaushal, G., Samurailatpam, S., Sahoo, D., Rai, A. K., et al. (2019). Metagenomic insights into the taxonomic and functional features of Kinema, a traditional fermented soybean product of Sikkim Himalaya. Front. Microbiol. 10:1744. doi: 10.3389/fmicb.2019.01744

Kumar, R., and Wyman, C. E. (2009). Effect of xylanase supplementation of cellulase on digestion of corn stover solids prepared by leading pre-treatment technologies. Bioresour. Technol. 100, 4203-4213. doi: 10.1016/j.biortech.2008. 11.057

Kumar, S., Haq, I., and Prakash, J. (2017). Purification, characterization and thermostability improvement of xylanase from Bacillus amyloliquefaciens and its application in pre-bleaching of kraft pulp. 3 Biotech 7:20.

Kumar, V., and Satyanarayana, T. (2011). Applicability of thermo-alkali-stable and cellulase-free xylanase from a novel thermo-halo-alkaliphilic Bacillus halodurans in producing xylo-oligosaccharides. Biotechnol. Lett. 33:2279. doi: 10.1007/s10529-011-0698-1 
Kumar, V., and Satyanarayana, T. (2012). Thermo-alkali-stable xylanase of a novel polyextremophilic Bacillus halodurans TSEV1 and its application in biobleaching. Int. Biodeterior. Biodegrad. 75, 138-145. doi: 10.1016/j.ibiod.2012. 09.007

Kumar, V., and Satyanarayana, T. (2014). Production of endoxylanase with enhanced thermostability by a novel polyextremophilic Bacillus halodurans TSEV1 and its applicability in waste paper deinking. Process Biochem. 49, 386-394. doi: 10.1016/j.procbio.2013.12.005

Kumar, V., Syal, P., and Satyanarayana, T. (2013a). Highly thermo-halo-alkalistable $\beta$-1,4-endoxylanase from a novel polyextremophilic strain of Bacillus halodurans. Bioprocess Biosyst. Eng. 36, 555-565. doi: 10.1007/s00449-0120811-4

Kumar, V., Verma, D., and Satyanarayana, T. (2013b). Extremophilic bacterial xylanases: production, characteristics and applications. Curr. Biotechnol. 2, 380-399. doi: 10.2174/18722083113076660027

Kwon, E. J., Jeong, Y. S., Kim, Y. H., Kim, S. K., Na, H. B., and Kim, J. (2010). Construction of a metagenomic library from compost and screening of cellulase and xylanase-positive clones. J. Appl. Biol. Chem. 53, 702-708. doi: 10.3839/ jksabc.2010.106

Lee, Y. E., Lowe, S. E., Henrissat, B., and Zeikus, J. G. (1993). Characterization of the active site and thermostability regions of endoxylanase from Thermoanaerobacterium saccharolyticum B6A-RI. J. Bacteriol. 175, 5890-5898. doi: $10.1128 /$ jb.175.18.5890-5898.1993

Li, H., Voutilainen, S., Ojamo, H., and Turunen, O. (2015). Stability and activity of Dictyoglomus thermophilum GH11 xylanase and its di-sulphide mutant at high pressure and temperature. Enzyme Microb. Technol. 70, 66-71. doi: 10.1016/j. enzmictec.2014.12.011

Li, N., Shi, P., Yang, P., Wang, Y., Luo, H., Bai, Y., et al. (2009). A xylanase with high $\mathrm{pH}$ stability from Streptomyces sp. S27 and its carbohydrate-binding module with/without linker-region-truncated versions. Appl. Microbiol. Biotechnol. 83, 99-107. doi: 10.1007/s00253-008-1810-x

Liavoga, A. B., Bian, Y., and Seib, P. A. (2007). Release of D-xylose from wheat straw by acid and xylanase hydrolysis and purification of xylitol. J. Agric. Food Chem. 55, 7758-7766.

Lin, X., Han, S., Zhang, N., Hu, H., Zheng, S., Ye, Y., et al. (2013). Bleach boosting effect of xylanase A from Bacillus halodurans C-125 in ECF bleaching of wheat straw pulp. Enzyme Microb. Technol. 52, 91-98. doi: 10.1016/j.enzmictec.2012. 10.011

Liu, N., Li, H., and Chevrette, M. G. (2019). Functional metagenomics reveals abundant polysaccharide-degrading gene clusters and cellobiose utilization pathways within gut microbiota of a wood-feeding higher termite. ISME J. 13, 104-117. doi: 10.1038/s41396-018-0255-1

Liu, T., Wang, Y., Luo, X., Li, J., Reed, S. A., Xiao, H., et al. (2016). Enhancing protein stability with extended disulfide bonds. Proc. Natl. Acad. Sci. U.S.A. 113, 5910-5915. doi: 10.1073/pnas.1605363113

Liu, W., Brennan, M. A., Serventi, L., and Brennan, C. S. (2017). Effect of cellulase, xylanase and $\alpha$-amylase combinations on the rheological properties of Chinese steamed bread dough enriched in wheat bran. Food Chem. 234, 93-102. doi: 10.1016/j.foodchem.2017.04.160

Liu, X., Huang, Z., Zhang, X., Shao, Z., and Liu, Z. (2014). Cloning, expression and characterization of a novel cold-active and halophilic xylanase from Zunongwangia profunda. Extremophiles 18, 441-450. doi: 10.1007/s00792-014$0629-\mathrm{x}$

Liu, X., Liu, T., Zhang, Y., Xin, F., Mi, S., Wen, B., et al. (2018). Structural insights into the thermophilic adaption mechanism of endo-1,4- $\beta$-xylanase from Caldicellulosiruptor owensensis. J. Agric. Food Chem. 66, 187-193. doi: 10.1021/acs.jafc.7b03607

Luthi, E., Love, D. R., and McAnulty, J. (1990). Cloning, sequence analysis, and expression of genes encoding xylan-degrading enzymes from the thermophile Caldocellum saccharolyticum. Appl. Env. Microbiol. 56, 1017-1024. doi: 10. 1128/aem.56.4.1017-1024.1990

Ma, R., Huang, H., Bai, Y., Luo, H., Fan, Y., and Yao, B. (2018). Insight into the cold adaptation and hemicellulose utilization of Cladosporium neopsychrotolerans from genome analysis and biochemical characterization. Sci. Rep. 8:6075.

Maalej, I., Belhaj, I., Masmoudi, N. F., and Belghith, H. (2009). Highly thermostable xylanase of the thermophilic fungus Talaromyces thermophilus: purification and charact-erization. Appl. Biochem. Biotechnol. 158, 200-212. doi: 10.1007/ s12010-008-8317-x
Mamo, G., Hatti-Kaul, R., and Mattiasson, B. (2006). A thermostable alkaline active endo- $\beta$-1-4-xylanase from Bacillus halodurans S7: purification and characterization. Enzyme Microb. Technol. 39, 1492-1498. doi: 10.1016/j. enzmictec.2006.03.040

Mamo, G., Thunnissen, M., Hatti-Kaul, R., and Mattiasson, B. (2009). An alkaline active xylanase: insights into mechanisms of high $\mathrm{pH}$ catalytic adaptation. Biochimie 91, 1187-1196. doi: 10.1016/j.biochi.2009.06.017

Marcolongo, L., La Cara, F., and Morana, A. (2015). Properties of an alkali-thermo stable xylanase from Geobacillus thermodenitrificans A333 and applicability in xylooligosaccharides generation. World J. Microbiol. Biotechnol. 31, 633-648.

Mathew, S., Aronsson, A., Karlsson, E. N., and Adlercreutz, P. (2018). Xylo- and arabino-xylo-oligosaccharides from wheat bran by endoxylanases, utilisation by probiotic bacteria, and structural studies of the enzymes. Appl. Microbiol. Biotechnol. 102, 3105-3120. doi: 10.1007/s00253-018-8823-x

Matteotti, C., Bauwens, J., Brasseur, C., Tarayre, C., and Thonart, P. (2012). Identification and characterization of a new xylanase from Gram-positive bacteria isolated from termite gut (Reticulitermes santonensis). Protein Expr. Purif. 83, 117-127. doi: 10.1016/j.pep.2012.03.009

McCarthy, A. A., Morris, D. D., Bergquist, P. L., and Baker, E. N. (2000). Structure of XynB, a highly thermostable beta-1,4-xylanase from Dictyoglomus thermophilum Rt46B.1, at $1.8 \mathrm{~A}^{\circ}$ resolution. Acta Crystallogr. D Biol. Crystallogr. 56, 1367-1375.

Menasria, T., Aguilera, M., Hocine, H., Benammar, L., Ayachi, A., Bachir, A. S., et al. (2018). Diversity and bioprospecting of extremely halophilic archaea isolated from Algerian arid and semi-arid wetland ecosystems for halophilicactive hydrolytic enzymes. Microbiol. Res. 207, 289-298. doi: 10.1016/j.micres. 2017.12.011

Merino, N., Aronson, H. S., Bojanova, D. P., Feyhl-Buska, J., Wong, M. L., Zhang, S., et al. (2019). Living at the Extremes: extremophiles and the limits of life in a planetary context. Front. Microbiol. 10:780. doi: 10.3389/fmicb.2019.0 0780

Mitra, S., Mukhopadhyay, B. C., Mandal, A. R., Arukha, A. P., Chakrabarty, K., Das, G. K., et al. (2015). Cloning, overexpression, and characterization of a novel alkali-thermostable xylanase from Geobacillus sp. WBI. J. Basic Microbiol. 55, 527-537. doi: 10.1002/jobm.201400495

Monica, P., and Kapoor, M. (2021). Alkali-stable GH-11 endo- $\beta-1,4$ xylanase (XynB) from Bacillus subtilis strain CAM 21: application in hydrolysis of agroindustrial wastes, fruit/vegetable peels and weeds. Prep. Biochem. Biotechnol. 51, 475-487. doi: 10.1080/10826068.2020.1830416

Mrabet, N. T., Van den Broeck, A., Van den brande, I., Stanssens, P., Laroche, Y. A., Lambeir, A., et al. (1992). Arginine residues as stabilizing elements in proteins. Biochemistry 31, 2239-2253. doi: 10.1021/bi00123a005

Nagar, S., Jain, R. K., Thakur, V. V., et al. (2013). Biobleaching application of cellulase poor and alkali stable xylanase from Bacillus pumilus SV-85S. 3 Biotech 3, 277-285. doi: 10.1007/s13205-012-0096-y

Nagar, S., Mittal, A., Kumar, D., and Gupta, V. K. (2012). Production of alkali tolerant cellulase free xylanase in high levels by Bacillus pumilus SV-205. Int. J. Biol. Macromol. 50, 414-420. doi: 10.1016/j.ijbiomac.2011.12.026

Nammori, T., Watanabe, T., Shinke, R., Kohno, A., and Kawamura, Y. (1990). Purification and properties of thermostable xylanase and $\beta$-xylosidase produced by a newly isolated Bacillus stearothermophilus strain. J. Bacteriol. 172, 66696672. doi: $10.1128 / \mathrm{jb}$.172.12.6669-6672.1990

Ninawe, S., Kapoor, M., and Kuhad, R. C. (2008). Purification and characterization of extracellular xylanase from Streptomyces cyaneus SN32. Bioresour. Technol. 99, 1252-1258. doi: 10.1016/j.biortech.2007.02.016

Oliveira, D. S., Telis-Romero, J., Da-Silva, R., and Franco, C. M. L. (2014). Effect of a Thermoascus aurantiacus thermostable enzyme cocktail on wheat bread quality. Food Chem. 143, 139-146. doi: 10.1016/j.foodchem.2013. 07.103

Oren, A. (2011). "Diversity of halophiles," in Extremophiles Handbook, eds K. Horikoshi, G. Antranikian, A. T. Bull, F. T. Robb, and K. O. Stetter (Japan: Springer), 309-325. doi: 10.1007/978-4-431-53898-1_14

Paes, G., Berrin, J. G., and Beaugrand, J. (2012). GH11 xylanases: structure/function/properties relationships and applications. Biotechnol. Adv. 30, 564-592. doi: 10.1016/j.biotechadv.2011.10.003

Passarinho, A. T. P., Ventorim, R. Z., Maitan-Alfenas, G. P., de Oliveira, E. B., and Guimaraes, V. M. (2019). Engineered GH11 xylanases from Orpinomyces sp. 
PC-2 improve techno-functional properties of bread dough. J. Sci. Food Agric. 99, 741-747.

Pinelo, M., Zeuner, B., and Meyer, A. S. (2010). Juice clarification by protease and pectinase treatments indicates new roles of pectin and protein in cherry juice turbidity. Food Bioproducts Process. 88, 259-265.

Polizeli, M. L., Rizzatti, A. C., Monti, R., Terenzi, H. F., Jorge, J. A., and Amorim, D. S. (2005). Xylanases from fungi: properties and industrial applications. Appl. Microbiol. Biotechnol. 67, 577-591.

Prakash, S., Veeranagouga, Y., Kyoung, L., and Sreeramulu, K. (2009). Xylanase production using inexpensive agricultural wastes and its partial characterization from a halophilic Chromohalobacter sp. TPSV 101. Process Biochem. 25, 197204. doi: 10.1007/s11274-008-9880-6

Prayogo, F. A., Budiharjo, A., Kusumaningrum, H. P., Wijanarka, W., Suprihadi, A., and Nurhayati, N. (2020). Metagenomic applications in exploration and development of novel enzymes from nature: a review. J. Genet. Eng. Biotechnol. 18:39.

Qing, Q., Yang, B., and Wyman, C. E. (2010). Xylo-oligomers are strong inhibitors of cellulose hydrolysis by enzymes. Bioresour. Technol. 101, 9624-9630. doi: 10.1016/j.biortech.2010.06.137

Qiu, H., Li, Z., Wang, H., Zhang, H., Li, S., Luo, X., et al. (2017). Molecular and biochemical characterization of a novel cold-active and metal ion-tolerant GH10 xylanase from frozen soil. Biotechnol. Biotechnol. Equip. 5, 955-963. doi: 10.1080/13102818.2017.1359667

Qu, W., and Shao, W. (2011). Cloning, expression and characterization of glycoside hydrolase family 11 endoxylanase from Bacillus pumilus ARA. Biotechnol. Lett. 33, 1407-1416. doi: 10.1007/s10529-011-0568-x

Rafiqul, I. S. M., Sakinah, A. M. M., and Karim, M. R. (2014). Production of xylose from meranti wood sawdust by dilute acid hydrolysis. Appl. Biochem. Biotechnol. 174, 542-555. doi: 10.1007/s12010-014-1059-Z

Rai, P., Majumdar, G. C., DasGupta, S., and De, S. (2003). Optimizing pectinase usage in pre-treatment of mosambi juice for clarification by response surface methodology. J. Food Eng. 64, 397-403. doi: 10.1016/j.jfoodeng.2003. 11.008

Rani, D. S., and Nand, K. (2000). Production of thermostable cellulase-free xylanase by Clostridium absonum CFR-702. Process Biochem. 36, 355-362. doi: 10.1016/ s0032-9592(00)00224-7

Rashamuse, K., Sanyika Tendai, W., Mathiba, K., Ngcobo, T., Mtimka, S., and Brady, D. (2016). Metagenomic mining of glycoside hydrolases from the hindgut bacterial symbionts of a termite (Trinervitermes trinervoides) and the characterization of a multi-modular $\beta$-1,4-xylanase (GH-11). Biotechnol. Appl. Biochem. 64, 174-186. doi: 10.1002/bab.1480

Renzetti, S., Courtin, C. M., Delcour, J. A., and Arendt, E. K. (2010). Oxidative and proteolytic enzyme preparations as promising improvers for oat bread formulations: rheological, biochemical and microstructural background. Food Chem. 4, 1465-1473. doi: 10.1016/j.foodchem.2009.09.028

Robledo, A., Aguilar, C. N., Belmares-Cerda, R. E., Flores-Gallegos, A. C., Contreras-Esquivel, J. C., Montanez, J. C., et al. (2016). Production of thermostable xylanase by thermophilic fungal strains isolated from maize silage. CyTA J. Food 14, 302-308. doi: 10.1080/19476337.2015.1105298

Rolland, J. L., Gueguen, Y., Flament, D., Pouliquen, Y., Street, P. F., and Dietrich, J. (2002). Comment on 'The first description of an archaeal hemicellulase: the xylanase from Thermococcus zilligii strain AN1': evidence that the unique $\mathrm{N}$-terminal sequence proposed comes from a maltodextrin phosphorylase. Extremophiles 6, 349-350. doi: 10.1007/s00792-001-0258-Z

Romero Victorica, M., Soria, M. A., Batista-García, R. A., Ceja-Navarro, J., Vikram, S., Ortiz, M., et al. (2020). Neotropical termite microbiomes as sources of novel plant cell wall degrading enzymes. Sci. Rep. 10:3864.

Saleem, M., Aslam, F., Akhtar, M. S., Tariq, M., and Rajoka, M. I. (2012). Characterization of a thermostable and alkaline xylanase from Bacillus sp. and its bleaching impact on wheat straw pulp. World J. Microbiol. Biotechnol. 28, 513-522. doi: 10.1007/s11274-011-0842-Z

Sanghvi, G., Jivrajani, M., Patel, N., Jivrajani, H., Bhaskara, G. B., and Patel, S. (2014). Purification and characterization of haloalkaline, organic solvent stable xylanase from newly isolated Halophilic Bacterium-OKH. Int. Sch. Res. Notices 2014:198251.

Sena, L. M., Morais, C. G., Lopes, M. R., Santos, R. O., Uetanabaro, A. P., Morais, P. B., et al. (2017). D-Xylose fermentation, xylitol production and xylanase activities by seven new species of Sugiyamaella. Ant. Van Leeuwenhoek 110, 53-67. doi: 10.1007/s10482-016-0775-5

Setati, M. E. (2010). Diversity and industrial potential of hydrolase-producing halophilic/halotolerant eubacteria. Afr. J. Biotechnol. 9, 1555-1560. doi: 10. 5897/ajb10.051

Shallom, D., and Shoham, Y. (2003). Microbial hemicellulases. Curr. Opin. Microbiol. 6, 219-228. doi: 10.1016/s1369-5274(03)00056-0

Sharma, A., Adhikari, S., and Satyanarayana, T. (2007). Alkali-thermostable and cellulase-free xylanase production by an extreme thermophile Geobacillus thermoleovorans. World J. Microbiol. Biotechnol. 23, 483-490. doi: 10.1007/ s11274-006-9250-1

Sharma, D., Agrawal, S., Yadav, R. D., and Mahajan, R. (2017). Improved efficacy of ultrafiltered xylanase-pectinase concoction in bio-bleaching of plywood waste soda pulp. 3 Biotech 7:2.

Sharma, K., and Chand, D. (2012). Purification and characterization of thermostable cellulase free xylanase from Pseudomonas Sp. XPB-6. Adv. Microbiol. 2, 17-25. doi: 10.4236/aim.2012.21003

Sharma, R., Oberoi, H. S., and Dhillon, G. S. (2016). "Fruit and vegetable processing waste: renewable feed stocks for enzyme production," in Agro-Industrial Wastes as Feedstock for Enzyme Production. Apply and Exploit the Emerging and Valuable Use Options of Waste Biomass, eds G. S. Dhillon and S. Kaur (London: Academic Press), 23-59. doi: 10.1016/b978-0-12-802392-1.00002-2

Sheng, P., Li, Y., Marshall, S. D. G., and Zhang, H. (2015). High genetic diversity of microbial cellulase and hemicellulase genes in the hindgut of Holotrichia parallela larvae. Int. J. Mol. Sci. 16, 16545-16559. doi: 10.3390/ijms16071 6545

Shi, H., Zhang, Y., Li, X., Huang, Y., Wang, L., Wang, Y., et al. (2013). A novel highly thermostable xylanase stimulated by $\mathrm{Ca} 2+$ from Thermotoga thermarum: cloning, expression and characterization. Biotechnol. Biofuels 6:26. doi: 10 . 1186/1754-6834-6-26

Shi, H., Zhang, Y., Zhong, H., Huang, Y., Li, X., and Wang, F. (2014). Cloning, overexpression and characterization of a thermo-tolerant xylanase from Thermotoga thermarum. Biotechnol. Lett. 36, 587-593. doi: 10.1007/s10529-013-1392-2

Shin, J. H., Choi, J. H., Lee, O. S., Kim, Y. M., Lee, D. S., and Kwak, Y. Y. (2009). Thermostable xylanase from Streptomyces thermocyaneoviolaceus for optimal production of xylo-oligosaccharides. Biotechnol. Bioprocess Eng. 14, 391-339.

Shirai, T., Suzuki, A., Yamane, T., Ashida, T., Kobayashi, T., Hitomi, J., et al. (1997). High-resolution crystal structure of M-protease: phylogeny aided analysis of the high-alkaline adaptation mechanism. Protein Eng. 10, 627-634. doi: 10.1093/ protein/10.6.627

Sinma, K., Khucharoenphaisan, K., Kitpreechavanich, V., and Tokuyama, S. (2011). Purification and characterization of a thermostable xylanase from Saccharopolyspora pathumthaniensis S582 isolated from the gut of a termite. Biosci. Biotechnol. Biochem. 75, 1957-1963. doi: 10.1271/bbb.110353

Sleat, R., Mah, R. A., and Robinson, R. (1984). Isolation and characterization of an anaerobic, cellulolytic bacterium, Clostridium cellulovorans sp. nov. Appl. Environ. Microbiol. 48, 88-93. doi: 10.1128/aem.48.1.88-93.1984

Smith, P. J., Wang, H. T., York, W. S., Peña, M., and Urbanowicz, B. R. (2017). Designer biomass for next-generation biorefineries: leveraging recent insights into xylan structure and biosynthesis. Biotechnol. Biofuels 10:286.

Sriprang, R., Asano, K., and Gobsuk, J. (2006). Improvement of thermostability of fungal xylanase by using site-directed mutagenesis. J. Biotechnol. 126, 454-462. doi: 10.1016/j.jbiotec.2006.04.031

Sriyapai, T., Somyoonsap, P., Matsui, K., Kawai, F., and Chansiri, K. (2011). Cloning of a thermostable xylanase from Actinomadura sp. S14 and its expression in Escherichia coli and Pichia pastoris. J. Biosci. Bioeng. 111, 528-536. doi: 10.1016/j.jbiosc.2010.12.024

Subramaniyan, S., and Prema, P. (2002). Biotechnology of microbial xylanases: molecular biology, and application. Crit. Rev. Biotechnol. 22, 33-64. doi: 10. 1080/07388550290789450

Sunna, A., and Antranikian, G. (1997). Xylanolytic enzymes from fungi and bacteria. Crit. Rev. Biotechnol. 17, 39-67. doi: 10.3109/07388559709146606

Sunna, A., and Bergquist, P. L. (2003). A gene encoding a novel extremely thermostable 1,4- $\beta$-xylanase isolated directly from an environmental DNA sample. Extremophiles 7, 63-70. doi: 10.1007/s00792-002-0296-1

Suryawanshi, R. K., Jana, U. K., Prajapati, B. P., and Kango, N. (2019). Immobilization of Aspergillus quadrilinetaus RSNK-1 multi-enzymatic system 
for fruit juice treatment and mannooligosaccharide generation. Food Chem. 289, 95-102. doi: 10.1016/j.foodchem.2019.03.035

Tatu, U., Braakman, I., and Helenius, A. (1993). Membrane glycoprotein folding, oligomerization and intracellular transport: effects of dithiothreitol in living cells. EMBO J. 12, 2151-2157. doi: 10.1002/j.1460-2075.1993.tb05863.x

Thidarat, N., Thongaram, T., Uengwetwanit, T., Pongpattanakitshote, S., and Eurwilaichitr, L. (2012). Metagenomic analysis of novel lignocellulose degrading enzymes from higher termite guts inhabiting microbes. J. Microbiol. Biotechnol. 22, 462-469. doi: 10.4014/jmb.1108.08037

Turunen, O., Vuorio, M., Fenel, F., and Leisola, M. (2002). Engineering of multiple arginines into the Ser/Thr surface of Trichoderma reesei endo-1,4-beta-xylanase II increases the thermotolerance and shifts the $\mathrm{pH}$ optimum towards alkaline pH. Protein Eng. 15, 141-145. doi: 10.1093/protein/15.2.141

Uhl, A. M., and Daniel, R. M. (1999). The first description of an archaeal hemicellulase: the xylanase from Thermococcus zilligii strain AN1. Extremophiles 3, 263-267. doi: 10.1007/s007920050126

Umemoto, H., Ihsanawati, Inami, M., Yatsunami, R., Fukui, T., Kumasaka, T., et al. (2009). Improvement of alkaliphilic of Bacillus alkaline xylanase by introducing amino acid substitutions both on catalytic cleft and protein surface. Biosci. Biotech. Biochem. 73, 965-967. doi: 10.1271/bbb.80869

Van Petegem, F., Collins, T., Meuwis, M. A., Gerday, C., Feller, G., and Van Beeumen, J. (2003). The structure of a cold-adapted family 8 xylanase at 1.3 $\AA$ resolution. Structural adaptations to cold and investigation of the active site. J. Biol. Chem. 278, 7531-7539.

Verma, D., Anand, A., and Satyanarayana, T. (2013a). Thermostable and alkalistable endoxylanase of the extremely thermophilic bacterium Geobacillus thermodenitrificans TSAA1: cloning, expression, characteristics and its applicability in generating xylooligosaccharides and fermentable sugars. Appl. Biochem. Biotechnol. 170, 119-130. doi: 10.1007/s12010-013-0 174-6

Verma, D., and Satyanarayana, T. (2012). Cloning, expression and applicability of thermo-alkali-stable xylanase of Geobacillus thermoleovorans in generating xylo-oligosaccharides from agro-residues. Bioresour. Technol. 107, 333-338. doi: 10.1016/j.biortech.2011.12.055

Verma, D., and Satyanarayana, T. (2013a). Improvement in thermostability of metagenomic GH-11 endoxylanase (Mxyl) by site-directed mutagenesis and its applicability in paper pulp bleaching process. J. Ind. Microbiol. Biotechnol. 40, 1373-1381. doi: 10.1007/s10295-013-1347-6

Verma, D., and Satyanarayana, T. (2013b). Production of cellulase-free xylanase by the recombinant Bacillus subtilis and its applicability in paper pulp bleaching. Biotechnol. Prog. 29, 1441-1447. doi: 10.1002/btpr.1826

Verma, D., and Satyanarayana, T. (2020). Xylanolytic extremozymes retrieved from environmental metagenomes: characteristics, genetic engineering, and applications. Front. Microbiol. 11:551109. doi: 10.3389/fmicb.2020.551109

Verma, D., Kawarabayasi, Y., Miyazaki, K., and Satyanarayana, T. (2013b). Cloning, expression and characteristics of a novel alkalistable and thermostable xylanase encoding gene (Mxyl) retrieved from compost-soil metagenome. PLoS One 8:e52459. doi: 10.1371/journal.pone.0052459

Verma, D., Kumar, R., and Satyanarayana, T. (2019). "Diversity in xylan-degrading prokaryotes and xylanolytic enzymes and their bioprospects," in Microbial Diversity in Ecosystem Sustainability and Biotechnological Applications, eds T. Satyanarayana, S. K. Das, and B. N. Johri (London: Springer Nature), 325-373. doi: 10.1007/978-981-13-8487-5_14

Vieille, C., and Zeikus, G. J. (2001). Hyperthermophilic enzymes: sources, uses, and molecular mechanisms for thermostability. Microbiol. Mol. Biol. Rev. 65, 1-43. doi: 10.1128/mmbr.65.1.1-43.2001

Viikari, L., Ranua, M., Kantelinen, A., Sundquist, J., and Linko, M. (1986). "Bleaching with enzymes," in Proceedings of the 3rd International Conference on Biotechnology. Pulp and Paper Industry, Stockholm, 67-69.

Wainø, M., and Ingvorsen, K. (2003). Production of $\beta$-xylanase and $\beta$-xylosidase by the extremely halophilic archaeon Halorhabdus utahensis. Extremophiles 7 , 87-93. doi: 10.1007/s00792-002-0299-y

Wakarchuk, W. W., Sung, W. L., Campbell, R. L., Cunningham, A., Watson, D. C., and Yaguchi, M. (1994). Thermostabilization of the Bacillus circulans xylanase by the introduction of disulfide bonds. Protein Eng. 7, 1379-1386.
Wang, H., Li, Z., Liu, H., Li, S., Qiu, H., Li, K., et al. (2017). Heterologous expression in Pichia pastoris and characterization of a novel GH11 xylanase from salinealkali soil with excellent tolerance to high $\mathrm{pH}$, high salt concentrations and ethanol. Protein Expr. Purif. 139, 71-77. doi: 10.1016/j.pep.2017.06.003

Wang, K., Cao, R., and Wang, M. (2019). A novel thermostable GH10 xylanase with activities on a wide variety of cellulosic substrates from a xylanolytic Bacillus strain exhibiting significant synergy with commercial Celluclast $1.5 \mathrm{~L}$ in pre-treated corn stover hydrolysis. Biotechnol. Biofuels. 12:48.

Wang, Q., Luo, Y., He, B., Jiang, L. S., Liu, J. X., and Wang, J. K. (2015). Characterization of a novel xylanase gene from rumen content of $\mathrm{Hu}$ sheep. Appl. Biochem. Biotechnol. 177, 1424-1436. doi: 10.1007/s12010-015-1823-8

Wang, S. Y., Hu, W., Lin, X. Y., Wu, Z. H., and Li, Y. Z. (2011). A novel cold-active xylanase from the cellulolytic myxobacterium Sorangium cellulosum So97331: gene cloning, expression, and enzymatic characterization. Appl. Microbiol. Biotechnol. 93, 1503-1512. doi: 10.1007/s00253-011-3480-3

Wang, S. Y., Hu, W., Lin, X. Y., Wu, Z. H., and Li, Y. Z. (2012). A novel cold-active xylanase from the cellulolytic myxobacterium Sorangium cellulosum So97331: gene cloning, expression, and enzymatic characterization. Appl. Microbiol. Biotechnol. 93, 1503-1512.

Warden, A. C., Williams, M., Peat, T. S., Seabrook, S. A., Newman, J., Dojchinov, G., et al. (2015). Rational engineering of a mesohalophilic carbonic anhydrase to an extreme halotolerant biocatalyst. Nat. Commun. 6:10278.

Winterhalter, C., Heinrich, P., Candussio, A., Wich, G., and Liebl, W. (1995). Identification of a novel cellulose-binding domain within the multidomain 120 kDa xylanase XynA of the hyperthermophilic bacterium Thermotoga maritima. Mol. Microbiol. 15, 431-444. doi: 10.1111/j.1365-2958.1995.tb02257.x

Wu, X., Zhang, Q., Zhang, L., Liu, S., Chen, G., Zhang, H., et al. (2020). Insights into the role of exposed surface charged residues in the alkali-tolerance of GH-11 xylanase. Front. Microbiol. 11:872. doi: 10.3389/fmicb.2020.00872

Xiang, L., Lu, Y., Wang, H., Wang, M., and Zhang, G. (2019). Improving the specific activity and $\mathrm{pH}$ stability of xylanase XynHBN188A by directed evolution. Bioresour. Bioprocess. 6:25.

Xiao, W., Li, H., Xia, W., Yang, Y., Hu, P., Zhou, S., et al. (2019). Co-expression of cellulase and xylanase genes in Sacchromyces cerevisiae toward enhanced bioethanol production from corn stover. Bioengineered 10, 513-521. doi: 10 . 1080/21655979.2019.1682213

Xiong, H., Fenel, F., Leisola, M., and Turunen, O. (2004). Engineering the thermostability of Trichoderma reesei endo-1,4-beta-xylanase II by combination of disulphide bridges. Extremophiles 8, 393-400. doi: 10.1007/ s00792-004-0400-9

Xu, Z., Li, S., Feng, X., Liang, J., and Xu, H. (2014). L-Arabinose isomerase and its use for biotechnological production of rare sugars. Appl. Microbiol. Biotechnol. 98:8869. doi: 10.1007/s00253-014-6073-0

Yadav, P., Maharjan, J., Korpole, S., Prasad, G. S., Sahni, G., Bhattarai, T., et al. (2018). Production, Purification, and characterization of thermostable alkaline xylanase from Anoxybacillus kamchatkensis NASTPD13. Front. Bioeng. Biotechnol. 6:65. doi: 10.3389/fbioe.2018.00065

Yan, S., Xu, Y., and Yu, X. (2021). Rational engineering of xylanase hyperproducing system in Trichoderma reesei for efficient biomass degradation. Biotechnol. Biofuels 14:90.

Yang, W., Yang, Y., and Zhang, L. (2017). Improved thermostability of an acidic xylanase from Aspergillus sulphureus by combined disulphide bridge introduction and proline residue substitution. Sci. Rep. 7:1587.

Yasuda, M., Nagai, H., Takeo, K., Ishii, Y., and Ohta, K. (2014). Bio-ethanol production through simultaneous saccharification and co-fermentation (SSCF) of a low-moisture anhydrous ammonia (LMAA)-pre-treated napiegrass (Pennisetum purpureum Schumach). Springer Plus 3:333. doi: 10.1186/21931801-3-333

You, S., Chen, C. C., Tu, T., Wang, X., Ma, R., Cai, H., et al. (2018). Insight into the functional roles of Glu175 in the hyperthermostable xylanase XYL10C- $\Delta \mathrm{N}$ through structural analysis and site-saturation mutagenesis. Biotechnol. Biofuels 11:159.

Yu, H., Zhao, S., Fan, Y., Hu, C., Lu, W., and Guo, L. (2019). Cloning and heterologous expression of a novel halo/alkali-stable multi-domain xylanase (XylM18) from a marine bacterium Marinimicrobium sp. strain LS-A18. Appl. Microbiol. Biotechnol. 8899-8909. doi: 10.1007/s00253-019-10140-6 
Zarafeta, D., Galanopoulou, A. P., Leni, M. E., Kaili, S. I., Chegkazi, M. S., Chrysina, E. D., et al. (2020). XynDZ5: a new thermostable GH-10 xylanase. Front. Microbiol. 11:545. doi: 10.3389/fmicb.2020.00545

Zeigler, D. R. (2014). The Geobacillus paradox: why is a thermophilic bacterial genus so prevalent on a mesophilic planet? Microbiology (Reading) 160, 1-11. doi: 10.1099/mic.0.071696-0

Zhang, G., Mao, L., Zhao, Y., Xue, Y., and Ma, Y. (2010). Characterization of a thermostable xylanase from an alkaliphilic Bacillus sp. Biotechnol. Lett. 32, 1915-1920. doi: 10.1007/s10529-010-0372-Z

Zhao, S., Bu, D., Wang, J., Liu, K., Zhu, Y., and Dong, Z. (2010). Novel glycoside hydrolases from a metagenome library of the rumen of Chinese holstein dairy cows. Appl. Environ. Microbiol. 76, 6701-6705. doi: 10.1128/aem. 00361-10

Zheng, H., Ming-zhe, S., Ling-cai, M., Hai-sheng, P., Xiu-qing, Z., Yan, Z., et al. (2014). Purification and characterization of a thermostable xylanase from Paenibacillus sp. NF1 and its application in xylo-oligosaccharides production. J. Microbiol. Biotechnol. 24, 489-496. doi: 10.4014/jmb.1312.12072

Zheng, Y., Li, Y., Liu, W., Chen, C., Ko, T., He, M., et al. (2016). Structural insight into potential cold adaptation mechanism through a psychrophilic glycoside hydrolase family 10 endo- $\beta-1,4$-xylanase. J. Struct. Biol. 193, 206-211. doi: $10.1016 /$ j.jsb.2015.12.010

Zhou, J., Wu, Q., Zhang, R., Mo, M., Tang, X., Li, J., et al. (2014). A thermo-halotolerant and proteinase-resistant endoxylanase from Bacillus sp. HJ14. Folia Microbiol. 59, 423-431. doi: 10.1007/s12223-014-0316-4
Zhu, D., Wu, Q., and Wang, N. (2011). "Industrial Enzymes," in Comprehensive Biotechnology, 2nd Edn, ed. M. Moo-Young (New York: Academic Press), 3-13. doi: 10.1007/1-4020-5377-0_1

Zverlov, V., Piotukh, K., Dakhova, O., Velikodvorskaya, G., and Borriss, R. (1996). The multidomain xylanase A of the hyperthermophilic bacterium Thermotoga neapolitana is extremely thermoresistant. Appl. Microbiol. Biotechnol. 45, 245247. doi: $10.1007 / \mathrm{s} 002530050678$

Conflict of Interest: The author declares that the research was conducted in the absence of any commercial or financial relationships that could be construed as a potential conflict of interest.

Publisher's Note: All claims expressed in this article are solely those of the authors and do not necessarily represent those of their affiliated organizations, or those of the publisher, the editors and the reviewers. Any product that may be evaluated in this article, or claim that may be made by its manufacturer, is not guaranteed or endorsed by the publisher.

Copyright (C) 2021 Verma. This is an open-access article distributed under the terms of the Creative Commons Attribution License (CC BY). The use, distribution or reproduction in other forums is permitted, provided the original author(s) and the copyright owner(s) are credited and that the original publication in this journal is cited, in accordance with accepted academic practice. No use, distribution or reproduction is permitted which does not comply with these terms. 